\title{
Guidance for the treatment and prevention of obstetric-associated venous thromboembolism
}

\author{
Shannon M. Bates ${ }^{1}$ - Saskia Middeldorp ${ }^{2}$ - Marc Rodger ${ }^{3}$ - Andra H. James ${ }^{4}$. \\ Ian Greer ${ }^{5}$
}

Published online: 16 January 2016

(c) The Author(s) 2016. This article is published with open access at Springerlink.com

\begin{abstract}
Venous thromboembolism (VTE), which may manifest as pulmonary embolism (PE) or deep vein thrombosis (DVT), is a serious and potentially fatal condition. Treatment and prevention of obstetric-related VTE is complicated by the need to consider fetal, as well as maternal, wellbeing when making management decisions. Although absolute VTE rates in this population are low, obstetric-associated VTE is an important cause of maternal morbidity and mortality. This manuscript, initiated by the Anticoagulation Forum, provides practical clinical guidance on the prevention and treatment of obstetric-associated VTE based on existing guidelines and consensus expert opinion based on available literature where guidelines are lacking.
\end{abstract}

Shannon M. Bates

batesm@mcmaster.ca

1 Department of Medicine, McMaster University and Thrombosis and Atherosclerosis Research Institute (TaARI), 1280 Main Street West, HSC 3W11, Hamilton, ON L8S 4K1, Canada

2 Department of Vascular Medicine, University of Amsterdam, Amsterdam, The Netherlands

3 Departments of Medicine, Epidemiology and Community Medicine, and Obstetrics and Gynecology, University of Ottawa, Ottawa, ON, Canada

4 Department of Obstetrics and Gynecology, Duke University, Durham, NC, USA

5 Faculty of Medical and Human Sciences, The University of Manchester, Manchester, UK
Keywords Pregnancy - Obstetric · Venous thromboembolism · Pulmonary embolism - Deep vein thrombosis · Prophylaxis · Anticoagulants

\section{Introduction}

Venous thromboembolism (VTE), which may manifest as pulmonary embolism (PE) or deep vein thrombosis (DVT), complicates $0.5-2.2$ per 1000 deliveries, depending on the population studied [1-8]. During pregnancy, the risk of VTE is increased five to tenfold compared to non-pregnant women of comparable age $[1,9,10]$. The postpartum period poses a higher risk $[1,7,10]$ and during this time frame, the daily risk of VTE is increased 15- to 35-fold compared to age-matched non-pregnant women $[1,9]$. The daily risk of pregnancy-associated VTE appears greatest during the first 3-6 weeks postpartum [1, 7]. After that, the risk declines rapidly, although a small residual risk increase may persist for 12 weeks after delivery [7, 10, 11]. Although the absolute VTE rates are low, pregnancy-associated VTE is an important cause of maternal morbidity [12-14] and mortality $[15,16]$.

The treatment and prevention of pregnancy-associated VTE is challenging because of the potential for both fetal and maternal complications, as well as the paucity of relevant high quality research. Although evidence-based guideline recommendations for the use of anticoagulants in this patient population have been published [17-25], they are based largely upon observational studies and extrapolated from data in non-pregnant patients. The lack of high quality data specific to pregnancy results in a lack of consistency in their recommendations. This chapter reviews the published evidence base and uses that information, as well as published guidelines, to provide practical 
guidance for the management and prevention of VTE during pregnancy.

\section{Methods}

The goal of this chapter is to provide guidance to providers on how best to individualize care to patients with pregnancy-associated VTE, with specific focus on the questions listed in Table 1. Questions were developed by consensus from the authors. To address these questions, current guidelines from the American College of Obstetricians and Gynecologists (ACOG) [17, 18], the Society of Obstetricians and Gynaecologists of Canada (SOGC) [19], the Royal College of Obstetricians and Gynaecologists (RCOG) [20, 21], clinicians from Australia and New Zealand [22], and American College of Chest Physicians (ACCP) [23-25] were reviewed and relevant recommendations were extracted (Tables 2A-2D). The literature was reviewed and data from relevant systematic reviews, randomized trials, and observational studies were incorporated. The authors' consensus interpretation of these studies, in the context of the realities of VTE care, was distilled into the practical recommendations that are presented in this article.

In making recommendations regarding the need for prophylaxis, the panel used a risk threshold of $3 \%$ and greater for antepartum prophylaxis and $3 \%$ and greater for postpartum prophylaxis. For risk factors for which only case control data are available, a relative risk of at least 30 -fold antepartum and 60-fold postpartum are required to reach our thresholds, assuming antepartum and postpartum baseline risks of 0.1 and $0.05 \%$, respectively [26]. The prophylaxis thresholds above were determined by the majority result of an anonymous vote of the authors. It is important to note that there was inconsistency between the authors in their risk threshold for recommending prophylaxis. For antepartum prophylaxis, three chose $3 \%$ or greater, one $5 \%$ or greater, and one $1 \%$ or greater. For postpartum prophylaxis, four selected a threshold of $3 \%$ or greater and one chose $1 \%$ or greater. The variability in risk thresholds is not surprising given the limitations of the available evidence, as well as the competing benefits and drawbacks of prophylaxis. The panel would emphasize that changes in the antepartum threshold to 5 or $1 \%$ and to the

Table 1 Guidance questions to be considered

1. What are the risks of anticoagulant use during pregnancy?

2. What are the risks of anticoagulation in breastfeeding women?

3. How is venous thromboembolism during pregnancy treated?

4. How is pregnancy-associated VTE prevented?

5. How is peripartum anticoagulation managed? postpartum threshold to $1 \%$ would markedly change the recommendations that follow. When making recommendations, the panel also took into account the estimated risks of major bleeding with prophylactic LMWH (antepartum: 0; $95 \%$ CI 0-0.6\% and postpartum: $0.3 \%$; $95 \%$ CI $0-1.0 \%$ ) [26]; the variability in risk estimates reported in the literature, the $95 \%$ confidence intervals around the risk estimates, and the strengths or weaknesses of relevant study methodology in addition to the above threshold limits.

\section{Guidance}

1. What are the risks of anticoagulant use during pregnancy?

During pregnancy, the risks posed to the fetus by anticoagulant therapy, as well as maternal efficacy and safety must be considered. Vitamin $\mathrm{K}$ antagonists cross the placenta and have the potential to cause teratogenicity as well as pregnancy loss, fetal bleeding, and neurodevelopmental deficits [27-34]. Discontinuation of vitamin K antagonists prior to the 6th week of gestation essentially eliminates the risk of warfarin embryopathy [29, 30, 32]. Pregnant women were excluded from participating in clinical trials evaluating the oral direct thrombin and factor Xa inhibitors (e.g. dabigatran, rivaroxaban, apixaban, edoxaban). These agents are likely to cross the placenta and their human reproductive risks are unknown [35-38]. Fondaparinux appears to cross the placenta in small quantities [39]. Reports of the successful use of fondaparinux in pregnant woman have been published [39-46] but it is important to recognize that many of these involve second trimester or later exposure.

Unfractionated heparin (UFH), low molecular weight heparin (LMWH) and danaparoid (a heparinoid) do not cross the placenta and are safe for the fetus [47-55]. Although UFH can be used during pregnancy for both prevention and treatment of thromboembolism, LMWH has a better safety profile than UFH [56, 57] and the incidence of bleeding and other complications (e.g. heparin induced thrombocytopenia [HIT], and heparin-associated osteoporosis) are lower in pregnant women receiving LMWH than with UFH [58-69]. LMWHs are eliminated primarily by renal excretion and may accumulate in patients with significant renal dysfunction. In the nonpregnant population, it has been suggested that therapeutic dose LMWH not be used in patients with significant renal impairment (e.g. a glomerular filtration rate (GFR) of less than $30 \mathrm{~mL} / \mathrm{min}$ ), although it is recognized that accumulation in patients with renal impairment may differ between the various LMWHs [70]. 
Table 2A Guideline summary-anticoagulant choice

\begin{tabular}{|c|c|c|c|c|}
\hline $\begin{array}{l}\text { American College } \\
\text { of Obstetricians } \\
\text { and Gynecologists } \\
(\mathrm{ACOG})[17,18]\end{array}$ & $\begin{array}{l}\text { Society of Obstetricians and } \\
\text { Gynaecologists of Canada } \\
\text { (SOGC) [19] }\end{array}$ & $\begin{array}{l}\text { Royal College of } \\
\text { Obstetricians and } \\
\text { Gynaecologists (RCOG) [20, } \\
21]\end{array}$ & $\begin{array}{l}\text { Australia/New Zealand } \\
\text { [22] }\end{array}$ & $\begin{array}{l}\text { American College of Chest } \\
\text { Physicians (ACCP) [23] }\end{array}$ \\
\hline \multicolumn{5}{|l|}{ During pregnancy } \\
\hline $\begin{array}{l}\text { Heparin } \\
\text { compounds are } \\
\text { the preferred } \\
\text { anticoagulant } \\
\text { during } \\
\text { pregnancy } \\
\text { (Level B) }\end{array}$ & $\begin{array}{l}\text { LMWH is the preferred } \\
\text { pharmacologic agent over } \\
\text { UFH for treatment of } \\
\text { VTE during pregnancy } \\
\text { (II-2A) } \\
\text { LMWH is the preferred } \\
\text { pharmacologic agent over } \\
\text { UFH for antepartum } \\
\text { thromboprophylaxis (III- } \\
\text { A) } \\
\text { LMWH is the preferred } \\
\text { pharmacologic agent over } \\
\text { UFH for postpartum } \\
\text { thromboprophylaxis } \\
\text { (IIIA) } \\
\text { Vitamin K antagonists } \\
\text { should only be considered } \\
\text { for treatment of VTE in } \\
\text { exceptional circumstances } \\
\text { (II-2A) } \\
\text { Recommend against the use } \\
\text { of oral Xa inhibitors and } \\
\text { oral direct thrombin } \\
\text { inhibitors (III-D) }\end{array}$ & $\begin{array}{l}\text { LMWH is the preferred } \\
\text { anticoagulant for treatment } \\
\text { of acute VTE during } \\
\text { pregnancy (B) } \\
\text { LMWHs are the agents of } \\
\text { choice for antenatal and } \\
\text { postnatal } \\
\text { thromboprophylaxis (A) } \\
\text { Because of their adverse } \\
\text { effects on the fetus, vitamin } \\
\text { K antagonists should not be } \\
\text { used for antenatal VTE } \\
\text { treatment (C) } \\
\text { Women receiving long-term } \\
\text { vitamin K antagonist } \\
\text { therapy should be } \\
\text { counselled about the risks of } \\
\text { vitamin K antagonists to the } \\
\text { fetus and advised to stop } \\
\text { these medications and } \\
\text { change to LMWH as soon as } \\
\text { pregnancy is confirmed } \\
\text { (ideally within } 2 \text { weeks of } \\
\text { the missed period and before } \\
\text { the 6th week of pregnancy) } \\
\text { (no grade) } \\
\text { Oral thrombin and Xa } \\
\text { inhibitors should be avoided } \\
\text { in pregnant women (no } \\
\text { grade) }\end{array}$ & $\begin{array}{l}\text { Women with VTE in } \\
\text { pregnancy should not be } \\
\text { treated with vitamin K } \\
\text { antagonists, such as } \\
\text { warfarin (Consensus } \\
\text { Level 1) }\end{array}$ & $\begin{array}{l}\text { For pregnant patients, } \\
\text { recommend LMWH for } \\
\text { prevention and treatment of } \\
\text { VTE, instead of UFH } \\
\text { (Grade 1B) } \\
\text { For pregnant women, } \\
\text { recommend avoiding the use } \\
\text { of oral direct thrombin and } \\
\text { factor Xa inhibitors (Grade } \\
\text { 1C) } \\
\text { For women requiring long- } \\
\text { term vitamin K antagonists } \\
\text { who are attempting } \\
\text { pregnancy and are } \\
\text { candidates for LMWH } \\
\text { substitution, suggest } \\
\text { performing frequent } \\
\text { pregnancy tests and } \\
\text { substituting LMWH for } \\
\text { vitamin K antagonists when } \\
\text { pregnancy is achieved rather } \\
\text { than switching to LMWH } \\
\text { while attempting pregnancy } \\
\text { (Grade 2C) [Remark: } \\
\text { Women who place little } \\
\text { value on avoiding the risks, } \\
\text { inconvenience, and costs of } \\
\text { LMWH therapy of uncertain } \\
\text { duration while awaiting } \\
\text { pregnancy and a high value } \\
\text { on minimizing the risks of } \\
\text { early miscarriage associated } \\
\text { with vitamin K antagonist } \\
\text { pregnapy are likely to choose } \\
\text { LMH while attempting }\end{array}$ \\
\hline \multicolumn{5}{|c|}{ During pregnancy if HIT or other heparin allergy } \\
\hline $\begin{array}{l}\text { Fondaparinux is } \\
\text { preferred if } \\
\text { there is severe } \\
\text { cutaneous } \\
\text { heparin allergy } \\
\text { or HIT (no } \\
\text { grade) }\end{array}$ & $\begin{array}{l}\text { Consultation with a } \\
\text { hematologist or } \\
\text { thrombosis specialist is } \\
\text { recommended to consider } \\
\text { the use of heparinoids if } \\
\text { HIT occurs (II-3B) }\end{array}$ & $\begin{array}{l}\text { Pregnant women who develop } \\
\text { HIT or have heparin allergy } \\
\text { and require continuing } \\
\text { anticoagulant therapy } \\
\text { should be managed an } \\
\text { alternative anticoagulant } \\
\text { under specialist advice (C) } \\
\text { Consideration should be } \\
\text { given to the use of } \\
\text { fondaparinux, argatroban, or } \\
\text { r-hirudin in pregnant women } \\
\text { who are unable to tolerate } \\
\text { heparin, UFH or danaparoid } \\
\text { and who require continuing } \\
\text { anticoagulant therapy (D) }\end{array}$ & & $\begin{array}{l}\text { For pregnant women, suggest } \\
\text { limiting the use of } \\
\text { fondaparinux and parenteral } \\
\text { direct thrombin inhibitors to } \\
\text { those with severe allergic } \\
\text { reactions to heparin (e.g. } \\
\text { HIT) who cannot receive } \\
\text { danaparoid (Grade 1C) }\end{array}$ \\
\hline
\end{tabular}


Table 2A continued

\begin{tabular}{|c|c|c|c|c|}
\hline $\begin{array}{l}\text { American College } \\
\text { of Obstetricians } \\
\text { and Gynecologists } \\
(\text { ACOG) }[17,18]\end{array}$ & $\begin{array}{l}\text { Society of Obstetricians and } \\
\text { Gynaecologists of Canada } \\
\text { (SOGC) [19] }\end{array}$ & $\begin{array}{l}\text { Royal College of } \\
\text { Obstetricians and } \\
\text { Gynaecologists (RCOG) [20, } \\
21]\end{array}$ & $\begin{array}{l}\text { Australia/New Zealand } \\
\text { [22] }\end{array}$ & $\begin{array}{l}\text { American College of Chest } \\
\text { Physicians (ACCP) [23] }\end{array}$ \\
\hline \multicolumn{5}{|l|}{ During breastfeeding } \\
\hline \multirow[t]{5}{*}{$\begin{array}{l}\text { Warfarin, } \\
\text { LMWH, } \\
\text { unfractionated } \\
\text { heparin are } \\
\text { compatible } \\
\text { with breast } \\
\text { feeding (Level } \\
\text { B) }\end{array}$} & & $\begin{array}{l}\text { Women should be advised } \\
\text { that neither UFH, LMWH } \\
\text { nor warfarin is } \\
\text { contraindicated in } \\
\text { breastfeeding (D) }\end{array}$ & & $\begin{array}{l}\text { For lactating women using } \\
\text { warfarin, acenocoumarol or } \\
\text { UFH who wish to } \\
\text { breastfeed, recommend } \\
\text { continuing the use of } \\
\text { warfarin, acenocoumarol, or } \\
\text { UFH (Grade 1A) }\end{array}$ \\
\hline & & & & $\begin{array}{l}\text { For lactating women using } \\
\text { LMWH, danaparoid, or } \\
\text { r-hirudin who wish to } \\
\text { breastfeed, recommend } \\
\text { continuing the use of } \\
\text { LMWH, danaparoid, or } \\
\text { r-hirudin (Grade 1B) }\end{array}$ \\
\hline & & & & $\begin{array}{l}\text { For breastfeeding women, } \\
\text { suggest alternative } \\
\text { anticoagulants rather than } \\
\text { fondaparinux (Grade 2C) }\end{array}$ \\
\hline & & & & $\begin{array}{l}\text { For breastfeeding women, we } \\
\text { recommend alternative } \\
\text { anticoagulants rather than } \\
\text { oral direct thrombin and } \\
\text { factor Xa inhibitors (Grade } \\
\text { 1C) }\end{array}$ \\
\hline & & & & $\begin{array}{l}\text { For lactating women using } \\
\text { low-dose Aspirin for } \\
\text { vascular indications who } \\
\text { wish to breastfeed, we } \\
\text { suggest continuing this } \\
\text { medication (Grade 1B) }\end{array}$ \\
\hline
\end{tabular}

Please see individual references for grading criteria

As outlined in Table 2A, there is clear consensus amongst the reviewed guideline documents that, in general, LMWH is the preferred anticoagulant for the management and treatment of VTE in pregnancy [17-25].

\section{Guidance Statement}

- Physicians should counsel women receiving long-term therapy with vitamin $K$ antagonists and the oral directacting anticoagulants about the fetal risks of these medications before pregnancy occurs.

- LMWH is the drug of choice for treatment and prevention of VTE in pregnancy, except in patients with HIT, a history of HIT, or significant renal dysfunction. UFH is preferred in patients with significant renal dysfunction.

- For women taking vitamin $K$ antagonists, two options are available to reduce the risk of warfarin embryopathy. The first is to advise women to perform frequent pregnancy tests and substitute LMWH for warfarin once pregnancy is achieved and before 6 weeks gestation. Alternatively, LMWH or UFH can be substituted for vitamin $K$ antagonists before conception is attempted. Although the latter approach minimizes the risks of early miscarriage associated with vitamin $K$ antagonist therapy, it lengthens the duration of exposure to LMWH or UFH and, therefore, is costly and exposes the patient to a greater burden of treatment associated with the use of injectable heparin therapy. Since warfarin embryopathy is unlikely to result from warfarin exposure before 6 weeks, the first option is usually favored by guidelines. Although the management of women who are receiving long-term therapy with oral direct thrombin and factor Xa inhibitors and attempting to conceive remains controversial, it has been suggested that these women should be converted to a coumarin or LMWH before conception is 
Table 2B Guideline summary-management of acute venous thromboembolism

\begin{tabular}{lllll}
\hline American College of & Society of Obstetricians & Royal College of & Australia/New Zealand & American College of \\
Obstetricians and & and Gynaecologists of & Obstetricians and & {$[22]$} & Chest Physicians (ACCP) \\
Gynecologists (ACOG) & Canada (SOGC) [19] & $\begin{array}{l}\text { Gynaecologists (RCOG) } \\
{[20,21]}\end{array}$ & & {$[23]$} \\
{$[17,18]$} & & & \\
\hline
\end{tabular}

\section{Hospitalization \\ Hospitalization in cases of hemodynamic instability, large VTE or maternal co- morbidity (no grade) \\ Pregnant women with acute VTE should be hospitalized or followed closely as outpatients for the first 2 weeks after diagnosis (III-C)}

\section{Anticoagulation \\ Therapeutic anticoagulation during current pregnancy \\ (Level C)}

Intravenous UFH can be considered in the initial treatment of PE and in situations in which delivery, surgery, or thrombolysis may be necessary (no grade)
Manufacturer's recommendations for LMWH dosing based on patient's current weight should be adhered to (II1A)

LMWH can be administered once or twice a day depending on the agent selected (IIIC)

Following initial treatment, anticoagulant intensity can be decreased to intermediate or prophylactic dose for the remainder of the pregnancy and for at least 6 weeks postpartum (III-C)

Intravenous UFH is the preferred treatment in massive PE with cardiovascular collapse (B)

Consideration should be given to the use of intravenous UFH when VTE occurs at term (D)
LMWH be given daily in the women's booking There is insufficient MW should be given divided

Inpatient observation and treatment of pregnant women with PE for the first few days following diagnosis is recommended (Consensus Level 1) 
Table 2B continued

\begin{tabular}{|c|c|c|c|c|}
\hline $\begin{array}{l}\text { American College of } \\
\text { Obstetricians and } \\
\text { Gynecologists (ACOG) [17, } \\
\text { 18] }\end{array}$ & $\begin{array}{l}\text { Society of } \\
\text { Obstetricians and } \\
\text { Gynaecologists of } \\
\text { Canada (SOGC) [19] }\end{array}$ & $\begin{array}{l}\text { Royal College of Obstetricians } \\
\text { and Gynaecologists (RCOG) } \\
{[20,21]}\end{array}$ & Australia/New Zealand [22] & $\begin{array}{l}\text { American } \\
\text { College of Chest } \\
\text { Physicians } \\
\text { (ACCP) [23] }\end{array}$ \\
\hline \multicolumn{5}{|l|}{ Managing of life threatening PE } \\
\hline $\begin{array}{l}\text { Intravenous UFH can be } \\
\text { considered in the initial } \\
\text { treatment of PE and } \\
\text { in situations in which } \\
\text { thrombolysis may be } \\
\text { necessary (no grade) }\end{array}$ & $\begin{array}{l}\text { Thrombolytic therapy } \\
\text { should only be } \\
\text { considered in limb- } \\
\text { threatening DVT or } \\
\text { massive PE (III-C) }\end{array}$ & $\begin{array}{l}\text { Collapsed shocked patients } \\
\text { should be assessed by a team } \\
\text { of experienced clinicians, } \\
\text { including the on-call } \\
\text { consultant obstetrician, who } \\
\text { should decide on an individual } \\
\text { basis whether a woman } \\
\text { receives intravenous UFH, } \\
\text { thrombolytic therapy or } \\
\text { thoracotomy and surgical } \\
\text { embolectomy. Management } \\
\text { should involve a } \\
\text { multidisciplinary team } \\
\text { including senior physicians, } \\
\text { obstetricians and radiologists } \\
\text { (no grade) } \\
\text { Intravenous UFH is the } \\
\text { preferred, initial treatment in } \\
\text { massive PE with } \\
\text { cardiovascular compromise } \\
\text { (B) } \\
\text { The on-call medical team } \\
\text { should be contacted } \\
\text { immediately. An urgent } \\
\text { portable echocardiogram or } \\
\text { CT pulmonary angiogram } \\
\text { within } 1 \text { h of presentation } \\
\text { should be arranged. If massive } \\
\text { PE is confirmed or, in extreme } \\
\text { circumstances prior to } \\
\text { confirmation, immediate } \\
\text { thrombolysis should be } \\
\text { considered (no grade) }\end{array}$ & $\begin{array}{l}\text { Thrombolysis should only be } \\
\text { considered in pregnancy for } \\
\text { women with life or limb- } \\
\text { threatening complications of } \\
\text { acute VTE (Consensus Level } \\
\text { I) }\end{array}$ & $\begin{array}{l}\text { Thrombolytic } \\
\text { therapy is best } \\
\text { reserved for } \\
\text { life- } \\
\text { threatening } \\
\text { VTE (no } \\
\text { grade) }\end{array}$ \\
\hline
\end{tabular}


Table 2B continued

\begin{tabular}{lllll}
\hline American & Society of Obstetricians and & Royal College of & Australia/New Zealand [22] & American College of Chest \\
$\begin{array}{l}\text { College of } \\
\text { Obstetricians } \\
\text { and }\end{array}$ & $\begin{array}{l}\text { Gynaecologists of Canada } \\
\text { (SOGC) [19] }\end{array}$ & $\begin{array}{l}\text { Obstetricians and } \\
\text { Gynaecologists (RCOG) [20, }\end{array}$ & Physicians (ACCP) [23] \\
Gynecologists & & $21]$ & \\
(ACOG) [17, & & & \\
$18]$ & & & \\
\hline
\end{tabular}

Graded compression stockings

Use of graded compression stockings can be considered for symptom relief in pregnant women with acute proximal DVT (III-C)

Treatment duration

Following acute VTE, therapeutic anticoagulation is recommended for a minimum of 3 months (IA)
In the initial management of DVT, the leg should be elevated and a graduated elastic compression stocking applied to reduce edema. Mobilization with graduated compression stockings should be encouraged (B)

Following a DVT, graduated compression stockings should be worn on the affected leg to reduce pain and swelling. Clinicians should be aware that the role of compression stockings in the prevention of post-thrombotic syndrome is unclear (B)

Treatment with therapeutic doses of subcutaneous LMWH should be employed during the remainder of the pregnancy (B)

Therapeutic anticoagulant therapy should be continued for the duration of the pregnancy and for at least 6 weeks postnatally and until at least 3 months of treatment has been given in total. Before discontinuing treatment, the continuing risk of thrombosis should be assessed (C)
All women with confirmed DVT should wear a belowknee class 2 (30-40 $\mathrm{mmHg}$ ) compression stocking for two years (Consensus Level I)

Anticoagulant therapy in pregnant women with acute proximal DVT and/or PE should be continued until at least 6 weeks postpartum or longer, if necessary, to complete a minimum total treatment period of 6 months (Consensus Level I)

A shorter total duration of therapy (6-8 weeks) may be appropriate in women with isolated distal DVT, with consideration given to prophylactic dose LMWH for the remainder of the pregnancy (Consensus Level I)
In patients with acute symptomatic DVT of the leg, suggest the use of compression stockings (Grade 2B) [24]
For pregnant women with acute VTE suggest that anticoagulants should be continued for at least 6 weeks postpartum for a minimum duration of therapy of 3 months) in comparison with shorter durations of treatment (Grade 2C) 
Table 2B continued

\begin{tabular}{|c|c|c|c|c|}
\hline $\begin{array}{l}\text { American College of } \\
\text { Obstetricians and } \\
\text { Gynecologists (ACOG) } \\
{[17,18]}\end{array}$ & $\begin{array}{l}\text { Society of Obstetricians } \\
\text { and Gynaecologists of } \\
\text { Canada (SOGC) [19] }\end{array}$ & $\begin{array}{l}\text { Royal College of } \\
\text { Obstetricians and } \\
\text { Gynaecologists (RCOG) } \\
{[20,21]}\end{array}$ & Australia/New Zealand [22] & $\begin{array}{l}\text { American College of Chest } \\
\text { Physicians (ACCP) [23] }\end{array}$ \\
\hline \multicolumn{5}{|l|}{ Insertion of IVC filter } \\
\hline $\begin{array}{l}\text { Women with } \\
\text { recurrent VTE } \\
\text { despite therapeutic } \\
\text { anticoagulation may } \\
\text { be candidates for } \\
\text { IVC filter placement } \\
\text { (no grade) }\end{array}$ & $\begin{array}{l}\text { IVC filters should only be } \\
\text { used in pregnant women } \\
\text { with acute PE or DVT } \\
\text { and contraindications to } \\
\text { anticoagulation (III-C) }\end{array}$ & $\begin{array}{l}\text { Consideration should be } \\
\text { given to the use of a } \\
\text { temporary IVC filter in } \\
\text { women with proven DVT } \\
\text { who have recurrent PE } \\
\text { despite adequate } \\
\text { anticoagulation and in } \\
\text { the peripartum period for } \\
\text { patients with iliac vein } \\
\text { DVT to reduce the risk of } \\
\text { PE (D) }\end{array}$ & $\begin{array}{l}\text { Insertion of a temporary } \\
\text { IVC filter should only be } \\
\text { considered in pregnant } \\
\text { patients with recent acute } \\
\text { venous thrombosis in } \\
\text { whom therapeutic } \\
\text { anticoagulation is } \\
\text { contraindicated because } \\
\text { of a high risk of bleeding } \\
\text { or who have objectively } \\
\text { confirmed recurrent VTE } \\
\text { despite therapeutic } \\
\text { anticoagulation } \\
\text { (Consensus Level I) }\end{array}$ & $\begin{array}{l}\text { Insertion of temporary IVC } \\
\text { filters is best restricted to } \\
\text { women with proven DVT } \\
\text { who have recurrent PE } \\
\text { despite adequate } \\
\text { anticoagulation (no } \\
\text { grade) }\end{array}$ \\
\hline \multicolumn{5}{|l|}{ Laboratory investigations } \\
\hline & $\begin{array}{l}\text { For pregnant women } \\
\text { initiated on LMWH, a } \\
\text { baseline platelet count } \\
\text { should be done and } \\
\text { repeated a week later to } \\
\text { screen for HIT (III-C) }\end{array}$ & $\begin{array}{l}\text { Routine measurement of } \\
\text { peak anti-Xa activity for } \\
\text { patients on LMWH for } \\
\text { treatment of acute VTE } \\
\text { in pregnancy or } \\
\text { postpartum is not } \\
\text { recommended except in } \\
\text { women at extremes of } \\
\text { body weight (less than } \\
50 \text { kg and } 90 \text { kg or more) } \\
\text { or with other } \\
\text { complicating factors (for } \\
\text { example with renal } \\
\text { impairment or recurrent } \\
\text { VTE) putting them at } \\
\text { high risk (C) } \\
\text { Routine platelet count } \\
\text { monitoring should not be } \\
\text { carried out (unless UFH } \\
\text { has been given) (D) }\end{array}$ & $\begin{array}{l}\text { There is insufficient } \\
\text { evidence to recommend } \\
\text { monitoring of anti-Xa } \\
\text { levels to guide dosing in } \\
\text { women on therapeutic } \\
\text { dose LMWH (Consensus } \\
\text { Level I) }\end{array}$ & $\begin{array}{l}\text { Suggest no routine } \\
\text { monitoring of LMWH } \\
\text { dosing with anti-Xa } \\
\text { LMWH (no grade) } \\
\text { For patients receiving } \\
\text { heparin in whom } \\
\text { clinicians consider the } \\
\text { risk of HIT to be }<1 \% \text {, } \\
\text { suggest that platelet } \\
\text { counts not be monitored } \\
\text { (Grade 2C) (estimated } \\
\text { incidence of HIT in } \\
\text { obstetrics patients, } \\
<0.1 \%)^{25}\end{array}$ \\
\hline
\end{tabular}

Please see individual references for grading criteria 
Table 2C Guideline summary-prevention of first and recurrent pregnancy-associated VTE

Pre-pregnancy counselling

SOGC: Individualized risk assessment for VTE before pregnancy, once pregnancy achieved, and as new clinical situations arise; consider patients' values and preferences (III-B)

RCOG: Documented risk assessment for VTE in early pregnancy or pre-pregnancy; repeat if hospitalization or other intercurrent problems; as well as intrapartum or postpartum $(\mathbf{C})$

Discuss risk of VTE and reasons for individuals recommendations with patients (no grade)

Thrombophilia testing

ACOG: Test for antiphospholipid antibodies (B) and inherited thrombophilias (C) when history of thrombosis

SOGC: No routine screening for inherited thrombophilias in women with first VTE in pregnancy (III-C)

Test for deficiencies of protein S, protein $\mathrm{C}$ and antithrombin following VTE in pregnancy if family history of those thrombophilias or thrombosis at unusual site (III-C)

Test for antiphospholipid antibodies if could affect duration of anticoagulation (III-C)

RCOG: Before testing, counsel women on implications of testing for themselves and family; interpretation of results should be conducted by clinician with specific expertise (no grade)

Test for antithrombin deficiency if family history of VTE and either antithrombin deficiency or no specific thrombophilia detected (no grade)

Test for antiphospholipid antibodies if unprovoked VTE (no grade)

Consider thrombophilia testing even if no personal history or risk factors for VTE in the presence of history of unprovoked or estrogenprovoked VTE in first-degree relative when aged $<50$ years; more informative if relative has known thrombophilia (D)

Heterozygosity for factor V leiden or prothrombin gene mutation

Antepartum

ACOG: Clinical surveillance or prophylactic LMWH or UFH (no grade)

SOGC: Clinical surveillance (no grade)

RCOG: Consider prophylaxis if $\geq 3$ other risk factors ${ }^{\mathrm{C}}$; consider prophylaxis from 28 weeks if 2 other risk factors ${ }^{\mathrm{C}}$ (D)

ACCP: Clinical surveillance (Grade 2C)

Postpartum

ACOG: Clinical surveillance or anticoagulation if risk factors ${ }^{\mathbf{A}}$ (no grade)

SOGC: Clinical surveillance or 6 weeks (II-3B) prophylaxis if any $\geq 1$ additional risk factors with absolute risk of VTE $<1 \%$ in isolation ${ }^{\mathrm{B}}$ (II-2B to III-B)

ROCG: Consider prophylaxis for at least 10 days if 1 other risk factor ${ }^{\mathrm{C}}$; consider extending to 6 weeks if family history of VTE (D)

AACP: Clinical surveillance if no family history; 6 weeks prophylaxis with prophylactic- or intermediate-dose LMWH or vitamin K antagonists targeted at INR 2.0 to 3.0 if family history (Grade 2C)

Protein $\mathrm{C}$ or S deficiency

Antepartum

ACOG: Clinical surveillance or prophylactic LMWH or UFH (no grade)

SOGC: Clinical surveillance (no grade)

RCOG: Refer to local expert; consider antenatal LMWH prophylaxis (D)

ACCP: Clinical surveillance (Grade 2C)

Postpartum

ACOG: Clinical surveillance or anticoagulation if risk factors ${ }^{\mathrm{A}}$ (no grade)

SOGC: Clinical surveillance or 6 weeks (II-3B) prophylaxis if any $\geq 1$ additional risk factors with absolute risk of VTE $<1 \%$ in isolation ${ }^{\mathrm{B}}$ (II-2B to III-B)

RCOG: 6 weeks postnatal prophylaxis (D)

ACCP: Clinical surveillance if no family history; 6 weeks postpartum prophylaxis with prophylactic- or intermediate-dose LMWH if family history (Grade 2C) 
Table 2C continued

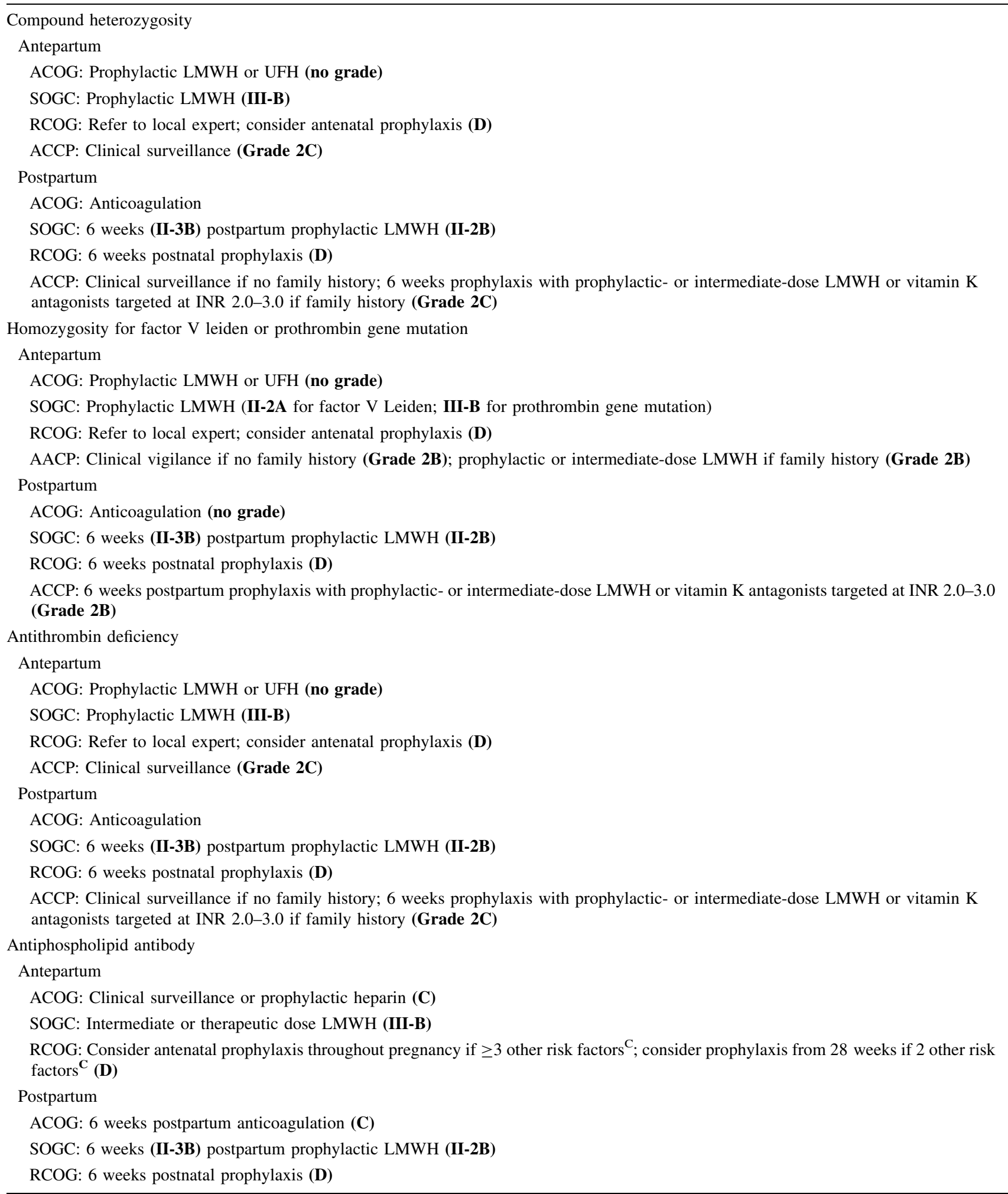


Table 2C continued

Clinical risk factors

Antepartum

SOGC: Assisted reproduction—no routine prophylaxis for ovulation induction (III-C); if severe ovarian hyperstimulation syndrome, prophylaxis with $\geq 8-12$ weeks LMWH after resolution (III-B); consider prophylaxis with LMWH if increased risk of VTE (III-B); nonobstetrical surgery during pregnancy_-prophylactic LMWH with duration dependent upon procedure and patient (III-B); strict bed restprophylactic LMWH if $\geq 7$ days and BMI $>25 \mathrm{~kg} / \mathrm{m}^{2}$ at first antenatal visit (II-2B); Multiple clinical risk factors-Prophylactic LMWH if absolute estimated VTE risk $>1 \%$, especially if bed rest (II-2B)

RCOG: Hospitalization—offer prophylaxis with LMWH unless contraindication such as risk of labor or active bleeding (D);

Hospitalization for hyperemesis-prophylaxis with LMWH and discontinue upon resolution (C); assisted reproduction-if ovarian hyperstimulation syndrome, prophylaxis with LMWH in first trimester $(\mathbf{C})$; if IVF pregnancy and 3 other risk factors ${ }^{\mathbf{C}}$, prophylaxis with LMWH in the first trimester $(\mathbf{C})$; Women with $\geq 4$ clinical risk factors ${ }^{\mathrm{C}}$ should be considered for antennal LMWH throughout pregnancy; if 3 risk factorsc, start prophylaxis at 28 weeks (D)

ACCP: Assisted reproduction—no routine thromboprophylaxis (Grade 1B); if severe ovarian hyperstimulation syndrome, 3 mo prophylactic LMWH after resolution (Grade 2C)

Postpartum

SOGC: Strict bed rest—prophylactic LMWH if $\geq 7$ days prior to delivery (II-2B); blood loss—prophylactic LMWH if $>1$ L peripartum or postpartum or requiring blood product replacement and concurrent postpartum surgery (II-2B); peripartum/postpartum infectionprophylactic LMWH (II-B); multiple clinical risk factors-6 weeks prophylaxis if risk factors ongoing or persistent (II-3B) and while hospitalized or up to 2 weeks if transient (III-C) if any $\geq 2$ risk factors with absolute risk of VTE $<1 \%$ in isolation ${ }^{\mathrm{B}}$ (II-2B to III-B) or $\geq 3$ risk factors with absolute risk of VTE of $<1 \%$ (II-2B to III-B)

RCOG: Prophylactic LMWH dosed by weight for 10 days after delivery (D) if class 3 obesity (BMI $\geq 40 \mathrm{~kg} / \mathrm{m}^{2}$ ) (D) or $\geq 2$ risk factors $\mathbf{C}$ (B)

Prevention of recurrent VTE

Single prior episode of VTE, not receiving long-term anticoagulation

Known Thrombophilia

Heterozygosity for Factor V Leiden or Prothrombin Gene Mutation

Antepartum

ACOG: Prophylactic- or intermediate-dose LMWH or UFH or clinical surveillance (no grade)

SOGC: Prophylactic LMWH (I-A if previous event provoked, II-2A if previous event unprovoked or related to oral contraceptives or pregnancy)

RCOG: Prophylactic LMWH throughout pregnancy $(\mathbf{C})$

ACCP: Low risk of recurrent VTE-(single episode associated with a transient risk factor not related to pregnancy or use of estrogen) clinical vigilance (Grade 2C); moderate to high risk of recurrent VTE-(single unprovoked VTE, pregnancy-or estrogen-related VTE, or multiple prior unprovoked VTE) not receiving long-term anticoagulation, prophylactic-or intermediate-dose LMWH (Grade 2C)

Postpartum

ACOG: Anticoagulation or intermediate dose LMWH or UFH (no grade)

SOGC: Postpartum 6 weeks (II-3B) prophylactic LMWH (II-2A)

ROCG: $\geq 6$ weeks thromboprophylaxis with LMWH or warfarin (B)

ACCP: 6 weeks prophylactic-or intermediate-dose LMWH or vitamin K antagonists targeted at an INR 2.0-3.0 (Grade 2B)

Protein $\mathrm{C}$ or S deficiency

Antepartum

ACOG: Prophylactic- or intermediate-dose LMWH or UFH or clinical surveillance (no grade)

SOGC: Prophylactic LMWH (I-A if previous event provoked, II-2A if previous event unprovoked or related to oral contraceptives or pregnancy)

RCOG: Prophylactic LMWH throughout pregnancy (C)

ACCP: Low risk of recurrent VTE-(single episode associated with a transient risk factor not related to pregnancy or use of estrogen) clinical vigilance (Grade 2C); moderate to high risk of recurrent VTE-(single unprovoked VTE, pregnancy-or estrogen-related VTE, or multiple prior unprovoked VTE) not receiving long-term anticoagulation, prophylactic-or intermediate-dose LMWH (Grade 2C)

Postpartum

ACOG: Anticoagulation or intermediate dose LMWH or UFH (no grade)

SOGC: Postpartum 6 weeks (II-3B) prophylactic LMWH (II-2A)

ROCG: $\geq 6$ weeks thromboprophylaxis with LMWH or warfarin (B)

ACCP: 6 weeks prophylactic-or intermediate-dose LMWH (Grade 2B) 
Table 2C continued

Compound heterozygosity

Antepartum

ACOG: Prophylactic-, intermediate-dose or adjusted-dose LMWH or UFH (no grade)

SOGC: Intermediate- or therapeutic-dose LMWH (III-B)

RCOG: Prophylactic LMWH (D)

ACCP: Same as for heterozygosity for factor V Leiden or prothrombin gene mutation

Postpartum

ACOG: 6 weeks anticoagulation or intermediate- or adjusted-dose LMWH or UFH (no grade)

SOGC: 6 weeks (II-3B) prophylactic LMWH (II-2B)

RCOG: Prophylaxis with LMWH or warfarin for at least 6 weeks after delivery (B)

ACCP: 6 weeks prophylactic-or intermediate-dose LMWH or vitamin K antagonists targeted at an INR 2.0 to 3.0 (Grade 2B)

Antithrombin deficiency

Antepartum

ACOG: Prophylactic-, intermediate-dose or adjusted-dose LMWH or UFH (no grade)

SOGC: Intermediate- or therapeutic-dose LMWH (III-B)

RCOG: Management should be undertaken in collaboration with hematologist with expertise in thrombosis in pregnancy and consideration given to antenatal anti-Xa monitoring and the potential for antithrombin replacement at initiation of labor or prior to caesarean section; if anti-Xa levels measured, a test that does not use exogenous antithrombin should be used with a 4-h peak level target of $0.5-1.0 \mathrm{iu} / \mathrm{ml}$ (no grade); higher dose LMWH (50 or $75 \%$ of treatment dose or weight-adjusted) (D)

ACCP: Same as for heterozygosity for factor V Leiden or prothrombin gene mutation

Postpartum

ACOG: 6 weeks anticoagulation or intermediate- or adjusted-dose LMWH or UFH (no grade)

SOGC: 6 weeks (II-3B) prophylactic LMWH (II-2B)

RCOG: 6 weeks of prophylaxis with higher dose LMWH (50, $75 \%$, full treatment dose) or until returned to oral anticoagulant therapy (B)

ACCP: 6 weeks prophylactic-or intermediate-dose LMWH or vitamin K antagonists targeted at an INR 2.0 to 3.0 (Grade 2B)

Antiphospholipid antibody

Antepartum

ACOG: Prophylactic anticoagulation with heparin throughout pregnancy $(\mathbf{C})$

SOGC: Intermediate or therapeutic dose LMWH (III-B)

RCOG: Management should be undertaken in collaboration with a hematologist and/or rheumatologist with relevant expertise in women with antiphospholipid antibody syndrome. These women require specialist management by an expert in thrombosis and pregnancy; higher dose LMWH (either 50, $75 \%$ or full treatment dose) (D)

ACCP: Same as for heterozygosity for factor V Leiden or prothrombin gene mutation

Postpartum

ACOG: 6 weeks anticoagulation with heparin $(\mathbf{C})$

SOGC: 6 weeks (II-3B) prophylactic LMWH (II-2B)

RCOG: 6 weeks thromboprophylaxis with higher dose LMWH (either 50, $75 \%$ or full treatment dose) or until returned to oral anticoagulant therapy (D)

ACCP: 6 weeks prophylactic-or intermediate-dose LMWH or vitamin K antagonists targeted at an INR 2.0 to 3.0 (Grade 2B) 
Table 2C continued

No known thrombophilia

Previous event associated with non-estrogen-related transient risk factor

Antepartum

ACOG: Clinical surveillance(no grade)

SOGC: Clinical surveillance (II-2A)

RCOG: If original VTE provoked by major surgery from which they have recovered and no other risk factors, thromboprophylaxis with LMWH withheld until 28 weeks with close surveillance for the development of other risk factors; if additional risk factors, offer LMWH (D); if original VTE related to nonsurgical transient risk factor, offer LMWH throughout the antenatal period (D)

ACCP: Low risk of recurrent VTE-(single episode associated with a transient risk factor not related to pregnancy or use of estrogen) clinical vigilance (Grade 2C)

Postpartum

ACOG: Anticoagulation (no grade)

SOGC: 6 weeks (II-3B) prophylactic LMWH (II-2A)

RCOG: Prophylaxis with LMWH or warfarin for at least 6 weeks after delivery (B)

ACCP: 6 weeks prophylactic-or intermediate-dose LMWH or vitamin K antagonists targeted at an INR 2.0 to 3.0 (if not protein C or S deficient) (Grade 2B)

Previous event associated with pregnancy or estrogen-related

\section{Antepartum}

ACOG: Prophylactic-dose LMWH or UFH (no grade)

SOGC: Prophylactic-dose LMWH (II-2A)

RCOG: Thromboprophylaxis with LMWH (D)

AACP: Moderate to high risk of recurrent VTE—(single unprovoked VTE, pregnancy-or estrogen-related VTE, or multiple prior unprovoked VTE) not receiving long-term anticoagulation, prophylactic-or intermediate-dose LMWH (Grade 2C)

Postpartum

ACOG: Anticoagulation (no grade)

SOGC: 6 weeks (II-3B) prophylactic LMWH (II-2A)

RCOG: Prophylaxis with LMWH or warfarin for at least 6 weeks after delivery (B)

ACCP: 6 weeks prophylactic-or intermediate-dose LMWH or vitamin $\mathrm{K}$ antagonists targeted at an INR 2.0 to 3.0 (if not protein C or S deficient) (Grade 2B)

Previous event unprovoked

\section{Antepartum}

ACOG: Prophylactic-dose LMWH or UFH (no grade)

SOGC: Prophylactic-dose LMWH (II-2A)

RCOG: Thromboprophylaxis with LMWH (D)

AACP: Moderate to high risk of recurrent VTE_(single unprovoked VTE, pregnancy-or estrogen-related VTE, or multiple prior unprovoked VTE) not receiving long-term anticoagulation, prophylactic-or intermediate-dose LMWH (Grade 2C)

Postpartum

ACOG: Anticoagulation (no grade)

SOGC: 6 weeks (II-3B) prophylactic LMWH (II-2A)

RCOG: Prophylaxis with LMWH or warfarin for at least 6 weeks after delivery (B)

ACCP: 6 weeks prophylactic-or intermediate-dose LMWH or vitamin $\mathrm{K}$ antagonists targeted at an INR 2.0 to 3.0 (if not protein C or S deficient) (Grade 2B) 
Table 2C continued

Two or more episodes, not receiving long-term anticoagulation

Antepartum

ACOG: Prophylactic- or intermediate-dose LMWH or UFH (no grade)

SOGC: As per single episode recommendations

RCOG: These patients require specialist management by an expert in thrombosis and pregnancy; higher-dose LMWH (50-75\% of treatment dose or weight adjusted) (D)

ACCP: Moderate to high risk of recurrent VTE_(single unprovoked VTE, pregnancy-or estrogen-related VTE, or multiple prior unprovoked VTE) not receiving long-term anticoagulation, prophylactic-or intermediate-dose LMWH (Grade 2C)

Postpartum

ACOG: 6 weeks anticoagulation or therapeutic-dose LMWH or UFH (no grade)

SOGC: As per single episode recommendations

RCOG: 6 weeks of prophylaxis with higher dose LMWH (50, $75 \%$ or full treatment dose) (D)

ACCP: 6 weeks prophylactic-or intermediate-dose LMWH or vitamin K antagonists targeted at an INR 2.0 to 3.0 (if not protein C or S deficient) (Grade 2B)

Two or more episodes, receiving long-term anticoagulation

Antepartum

ACOG: Therapeutic-dose LMWH or UFH (no grade)

SOGC: Therapeutic dose LMWH (III-B)

RCOG: Women should be counselled about the risks of vitamin K antagonists to the fetus and advised to stop these medications and change to LMWH as soon as pregnancy is confirmed (ideally within 2 weeks of the missed period and before the 6th week of pregnancy) (no grade). Thromboprophylaxis with higher dose LMWH (either 50, $75 \%$ or full treatment dose) (D)

ACCP: If taking long-term vitamin K antagonists and candidates for LMWH substitution, suggest performing frequent pregnancy tests and substituting LMWH for vitamin K antagonists only when pregnancy achieved (2C) [Remark: women who place little value on avoiding the risks, inconvenience and costs of LMWH therapy of uncertain duration while awaiting pregnancy and a high value on minimizing the risks of miscarriage associated with vitamin $\mathrm{K}$ antagonists are likely to choose LMWH while attempting pregnancy]. Suggest adjusteddose or therapeutic dose of LMWH (Grade 2C)

Postpartum

ACOG: Resumption of long-term anticoagulation (no grade)

SOGC: Resumption of long-term anticoagulation (no grade)

RCOG: Thromboprophylaxis with higher dose LMWH (either 50, $75 \%$ or full treatment dose) for 6 weeks or until returned to oral anticoagulant therapy after delivery (D). Warfarin can be restarted in women receiving long-term anticoagulation with this agent when the risk of bleeding is reduced; usually 5-7 days after delivery (no grade)

ACCP: Suggest resumption of long-term anticoagulants, rather than prophylactic LMWH (Grade 2C)

Prevention of VTE associated with caesarean section

ACOG: Placement of pneumatic compression devices before caesarean delivery if not already receiving thromboprophylaxis (C)

SOGC: Following emergency caesarean section-if risk factors each with an absolute risk $<1 \%$ risk of VTE in isolation (other than cesarean section) ${ }^{\mathbf{B}}$, consider LMWH prophylaxis (II-2B to III-B); following elective caesarean section-if $\geq 2$ risk factors each with an absolute risk of VTE of $<1 \%$ (other than cesarean section) $)^{\mathbf{D}}$, consider LMWH (II-2B to III-B); 6 weeks postpartum prophylaxis if risk persistent (II-3B), while risk factors ongoing, and during hospitalization; up to 2 weeks postpartum prophylaxis if risk transient (III-C)

RCOG: Emergency caesarean section-10 day thromboprophylaxis with LMWH after delivery (C); all other patients undergoing caesarean section-consider 10 days thromboprophylaxis with LMWH after delivery if additional risk factors ${ }^{\mathrm{E}}$ (C)

ACCP: No additional risk factors-no prophylaxis other than early mobilization (Grade 1B); 1 major risk factor ${ }^{\mathrm{F}}$ or $\geq 2$ minor risk factors ${ }^{\mathrm{G}}$ (1 minor if emergency caesarean section) - (risk of postpartum VTE of $>3 \%$ ), suggest prophylactic LMWH (if contraindication to anticoagulation use mechanical prophylaxis (elastic stockings or intermittent pneumatic compression) while in hospital following delivery (Grade 2B) [Remark: the reduced risk of bleeding with mechanical prophylaxis should be weighed against inconvenience of elastic stockings and intermittent pneumatic compression]; very high risk with multiple additional risk factors persisting in puerperiumcombine prophylactic LMWH with elastic stockings and/or intermittent pneumatic compression (Grade 2C); selected high risk patients with significant risk factors persisting after delivery — up to 6 weeks extended prophylaxis after delivery following hospital discharg (Grade 2C)

Please see individual references for grading criteria 
Table 2D Guideline summary—anticoagulant management around the time of delivery

\begin{tabular}{lllll}
\hline American College of & Society of Obstetricians & Royal College of & Australia/New Zealand & American College of \\
Obstetricians and & and Gynaecologists of & Obstetricians and & {$[22]$} & Chest Physicians (ACCP) \\
Gynecologists (ACOG) & Canada (SOGC) [19] & Gynaecologists (RCOG) & & {$[23]$} \\
{$[17,18]$} & & {$[20,21]$} & \\
\hline
\end{tabular}

Antepartum: general guidance

Women receiving prophylactic, intermediate-dose, or therapeutic anticoagulation should have a discussion about options for analgesia/ anaesthesia prior to delivery (III-B)

\author{
Women on LMWH for \\ treatment of VTE should \\ be advised that once she \\ is in established labour \\ or thinks she is in labour, \\ she should not inject any \\ further heparin (no \\ grade) \\ LMWH maintenance \\ therapy should be \\ discontinued $24 \mathrm{~h}$ prior \\ to planned delivery \\ (induction of labour or \\ caesarean section) (D)
}

Antepartum: conversion to UFH

$$
\begin{aligned}
& \text { Women receiving } \\
& \text { therapeutic or } \\
& \text { prophylactic LMWH } \\
& \text { may be converted to } \\
& \text { unfractionated heparin } \\
& \text { in the last month of } \\
& \text { pregnancy or sooner if } \\
& \text { delivery appears } \\
& \text { imminent (Level C) or } \\
& \text { planned delivery with } \\
& \text { withholding of } \\
& \text { anticoagulants for } 24 \mathrm{~h} \\
& \text { (no grade) }
\end{aligned}
$$

Planned delivery with conversion to intravenous UFH in anticipation of delivery may be required to minimize the time off anticoagulants for women at the highest risk of recurrent VTE (no grade)
Delivery options in women using anticoagulants are best considered by a multidisciplinary team. Several options are possible, including spontaneous labour and delivery, induction of labor, and elective caesarean section. The plan for delivery should take into account obstetric, hematologic, and anesthetic considerations (no grade)

Women at very high risk for recurrent VTE (e.g. proximal DVT or PE close to the expected date of delivery may benefit by having a planned delivery by induction or caesarean section as appropriate, so that the duration of time without anticoagulation can be minimized (no grade)

Women at highest risk of recurrent VTE (e.g. proximal DVT or PE within 2 weeks) can be switched to intravenous UFH prior to planned delivery, which is then discontinued $4-6 \mathrm{~h}$ prior to the expected time of delivery or epidural insertion (no grade)

Antepartum: Laboratory Investigations
A recent platelet count should be available on admission in labour or before caesarean delivery in women who have been, or are, on anticoagulants (III-B) 
Table 2D continued

\begin{tabular}{lllll}
\hline American College of & $\begin{array}{l}\text { Society of Obstetricians } \\
\text { and Gynaecologists of }\end{array}$ & $\begin{array}{l}\text { Royal College of } \\
\text { Obstetricians and }\end{array}$ & Australia/New Zealand & $\begin{array}{l}\text { American College of } \\
\text { Chest Physicians (ACCP) } \\
\text { Gynecologists (ACOG) }\end{array}$ \\
$\begin{array}{l}\text { Canada (SOGC) [19] } \\
{[17,18]}\end{array}$ & $\begin{array}{l}\text { Gynaecologists (RCOG) } \\
{[20,21]}\end{array}$ & {$[23]$} & \\
\hline
\end{tabular}

Antepartum: timing of neuraxial blockade after last dose of LMWH/UFH

It is recommended to withhold neuroaxial blockade for $10-12 \mathrm{~h}$ after the last prophylactic dose of LMWH or $24 \mathrm{~h}$ after the last therapeutic dose of LMWH (Level C)

Discontinue prophylactic or intermediate dose LMWH or UFH upon the onset of spontaneous labour or the day prior to a planned induction of labour or caesarean section (II-3B)
For women on LMWH, neuroaxial anesthesia can be administered a minimum of $10-12 \mathrm{~h}$ after the last prophylactic dose (III-B) or at least $24 \mathrm{~h}$ after the last therapeutic dose (III-B)

For women on UFH, neuroaxial anesthesia can be administered after no delay following a prophylactic dose (maximum 10,000 units/day) (III-B), at least $4 \mathrm{~h}$ after stopping a therapeutic intravenous infusion (and when the activated partial thromboplastin time is normal) (III-B), and $12 \mathrm{~h}$ or longer after the last therapeutic subcutaneous dose (and when the activated partial thromboplastin time is normal) (III-B)

Neuroaxial anesthesia must be avoided in a women who is fully anticoagulated or in whom there is evidence of altered coagulation (II-3A)
Women taking LMWH should be advised that once she is in established labour or thinks she is in labour, she should not inject any further heparin (no grade)

Where delivery is planned, LMWH therapy should be discontinued $24 \mathrm{~h}$ prior to delivery (no grade). Regional anesthesia or analgesic techniques should not be taken until at least $24 \mathrm{~h}$ after the last dose of therapeutic LMWH (no grade) and at least $12 \mathrm{~h}$ after the last dose of prophylactic LMWH (no grade)
For prophylactic LMWH, a minimum of $12 \mathrm{~h}$ after LMWH dose is required prior to performance of neuroaxial blockade (no grade). Wait at least $2 \mathrm{~h}$ following neuroaxial blockade or catheter removal before giving subsequent dose (no grade)

For therapeutic LMWH, a minimum of $24 \mathrm{~h}$ after LMWH dose is required before performance of neuroaxial blockade (no grade)

For prophylactic UFH ( $\leq 10,000$ units daily), wait at least $6 \mathrm{~h}$ after last dose before performing neuroaxial blockade (no grade). Wait at least $2 \mathrm{~h}$ after performing neuroaxial blockage or removing neuroaxial catheter before giving next dose (no grade)

For therapeutic UFH, stop intravenous UFH 4-6 h prior to performing neuroaxial blockade and document a normal activated partial thromboplastin time (3-4 h after stopping infusion)(no grade). Wait at least $1 \mathrm{~h}$ after performing neuroaxial blockage or removing neuroaxial catheter before restarting UFH (no grade)
For pregnant women receiving adjusted-dose LMWH and where delivery is planned, recommend discontinuation of LMWH at least $24 \mathrm{~h}$ prior to induction of labour or caesarean section (or expected time of neuroaxial anesthesia) rather than continuing LMWH up until the time of delivery (Grade 1B)

If spontaneous labour occurs in women receiving anticoagulation, neuroaxial anesthesia should not be used. Where the level of anticoagulation is uncertain and where laboratory support allows for rapid assessment of heparin levels, then testing can be considered to guide anesthetic and surgical management (no grade) 
Table 2D continued

\begin{tabular}{lllll}
\hline American College of & Society of Obstetricians & Royal College of & Australia/New Zealand & American College of \\
Obstetricians and & and Gynaecologists of & Obstetricians and & [22] & Chest Physicians (ACCP) \\
Gynecologists (ACOG) & Canada (SOGC) [19] & $\begin{array}{l}\text { Gynaecologists (RCOG) } \\
{[20,21]}\end{array}$ & {$[23]$} & \\
{$[17,18]$} & & & \\
\hline
\end{tabular}

Antepartum: insertion of IVC filter

Women with DVT

within 2-4 weeks

before delivery may be

candidates for

placement of a

retrievable IVC filter

(no grade)
Consideration should be given to the use of a temporary IVC filter in the perinatal period for women with iliac vein DVT to reduce the risk of PE (no grade)

Postpartum: general advice-including management of women at high risk of hemorrhage

When reinstitution of anticoagulant therapy is planned postpartum, pneumatic

compression devices should be left in place until the patient is ambulatory and until anticoagulation is restarted (Level C)
In women receiving therapeutic doses of LMWH, wound drain (abdominal and rectus sheath) should be considered at caesarean section and the skin incision should be closed with staples or interrupted sutures to allow for drainage of any hematoma (no grade)

Any women who is considered to be at high risk of hemorrhage and in whom continued heparin treatment is considered essential should be manage with intravenous UFH until the risk factors for hemorrhage have resolved (no grade)
Women at highest risk of recurrent VTE (e.g. proximal DVT or PE within 2 weeks) can have a temporary IVC filter inserted prior to planned delivery and removed postpartum (no grade) 
Table 2D continued

\begin{tabular}{llll}
\hline $\begin{array}{l}\text { American College of Obstetricians } \\
\text { and Gynecologists (ACOG) [17, 18] }\end{array}$ & $\begin{array}{l}\text { Society of Obstetricians and } \\
\text { Gynaecologists of Canada (SOGC) } \\
{[19]}\end{array}$ & $\begin{array}{l}\text { Royal College of Obstetricians and } \\
\text { Gynaecologists (RCOG) [20, 21] }\end{array}$ & $\begin{array}{l}\text { Australia/ } \\
\text { New American } \\
\text { Cealand }\end{array}$ \\
& & & $\begin{array}{l}\text { College of } \\
\text { Phest }\end{array}$ \\
& & [22] & Physicians \\
(ACCP) [23]
\end{tabular}

Postpartum: timing of resumption of anticoagulant therapy

Resumption of anticoagulation therapy no sooner than $4-6 \mathrm{~h}$ after vaginal delivery or 6-12 h after caesarean delivery is a reasonable approach to minimize bleeding complications (Level B)
Removal of a neuraxial catheter left in situ postpartum should only be undertaken $4,10,12$, or $24 \mathrm{~h}$ following the administration of prophylactic dose UFH (maximum 10,000 units daily), prophylactic dose LMWH (single daily dose), or therapeutic dose LMWH, respectively; or in the case of therapeutic dose UFH when the activated partial thromboplastin time is normal (II-3B)

Prophylactic LMWH (single daily dose) may be started/restarted $4 \mathrm{~h}$ after neuroaxial catheter removal, provided there is full neurologic recovery and no evidence of activated bleeding or coagulopathy (III-B)

Therapeutic LMWH may be started/ restarted at least $24 \mathrm{~h}$ after a single injection neuroaxial block and a minimum of $4 \mathrm{~h}$ after neuroaxial catheter removal, provided there is full neurologic recovery and no evidence of activated bleeding or coagulopathy (III-B)

Subcutaneous UFH may be started/ restarted at least $1 \mathrm{~h}$ after a single injection neuroaxial block, provided there is full neurologic recovery and no evidence of activated bleeding or coagulopathy (III-B)

Concomitant antiplatelet agents (acetylsalicylic acid or nonsteroidal anti-inflammatory drugs) should not be administered concomitantly with heparin if a neuroaxial catheter is left in situ postpartum (III-D)

Women on therapeutic anticoagulation who have received neuroaxial anesthesia should be monitored closely for the development of spinal hematoma (III-B)
The first prophylactic dose of LMWH should be given as soon as possible after delivery provided there is no postpartum hemorrhage and regional anesthesia has not been used (no grade)

LMWH should not be given for $4 \mathrm{~h}$ after the use of spinal anesthesia or after the epidural catheter has been removed and the epidural catheter should not be removed within $12 \mathrm{~h}$ of the most recent injection (D)

Women should be offered a choice of LMMH or vitamin $\mathrm{K}$ antagonists for postnatal therapy after discussion about the need for regular blood tests for monitoring warfarin, particularly during the first 10 days of treatment (no grade)

Initiation of warfarin should be avoided until at least the 5th day and for longer in women at increased risk of postpartum hemorrhage (no grade)

Please see individual references for grading criteria

ACOG American College of Obstetricians and Gynecologists, ACCP American College of Chest Physicians, ART Assisted reproductive technology, $D V T$ deep vein thrombosis, $H I T$ heparin-induced thrombocytopenia, IVF In vitro fertilization, $I V C$ inferior vena cava, $L M W H$ low molecular weight heparin, RCOG Royal College of Obstetricians and Gynaecologists, SOGC Society of Obstetricians and Gynecologists of Canada, $P E$ pulmonary embolism, UFH unfractionated heparin, VTE venous thromboembolism 
attempted; failing that, the switch should be made as soon as pregnancy is confirmed.

- In pregnant women with severe cutaneous allergies to UFH or LMWH or with HIT or a history of HIT, danaparoid or fondaparinux (if danaparoid not available) may be used. Appropriate dosage and management of these anticoagulants around the time of delivery should be discussed with a hematologist or thrombosis specialist.

2. What are the risks of anticoagulation in breastfeeding women?

Neither warfarin, the most commonly used vitamin $\mathrm{K}$ antagonist in North America and the United Kingdom nor acenocoumarol, which is commonly used in Europe, is detected in breast milk and neither medication induces an anticoagulant effect in the breast-fed infant when nursing mothers consume the drug [71-74]. Phenprocoumon, another vitamin $\mathrm{K}$ antagonist with a long half-life, is also widely used outside of North America. This agent is more lipophilic than warfarin and acenocoumarol and so can be excreted into breast milk, although since it is highly protein-bound, the amounts detected are small [75, 76]. Small amounts of LMWH have been detected in the breast milk of women receiving this medication [77]; however, given the very low bioavailability of heparin when ingested orally [78], there is unlikely to be any clinically relevant effect on the nursing infant. All of the guidelines that address the issue of anticoagulant use during breastfeeding agree that warfarin, LMWH, and UFH are safe to use in this setting (see Table 2A) [17, 20-22]. Phencoumaron should be reserved for women who are unstable on shortacting acenocoumarol in countries where warfarin is not available [76].

According to the manufacturer's prescribing information, fondaparinux was excreted in the milk of lactating rats [79]. There are no published data on the excretion of fondaparinux into human milk and the effects on the nursing infant are unknown. The manufacturer recommends that caution be used when administering fondaparinux to breastfeeding women [79]. That said, significant absorption by the nursing infant would be unlikely as orally ingested heparins have low bioavailability [78].

There are no clinical data on the effect of maternally ingested oral direct thrombin and factor $\mathrm{Xa}$ inhibitors on breastfed infants. The manufacturers of these agents all recommend against using these medications in breastfeeding women [35-37].

\section{Guidance Statement}

- UFH, LMWH, warfarin and acenocoumarol are safe for the breast-fed infant when administered to the nursing mother.
- The oral direct thrombin and factor Xa inhibitors should not be used while breastfeeding.

3. How is venous thromboembolism during pregnancy treated?

The guideline recommendations for management of acute VTE during pregnancy are summarized in Table 2B. There have been no large studies examining the safety and efficacy of outpatient treatment of VTE diagnosed during pregnancy. Data from the non-pregnant population suggest that outpatient DVT treatment is not associated with an increase in mortality, recurrent VTE, or major bleeding [24]. In non-pregnant patients with acute DVT, outpatient treatment is recommended as long as the patient feels well enough to be treated at home (e.g. does not have severe leg symptoms or comorbidity) and has well-maintained living conditions, strong support from family or friends, telephone access, and the ability to quickly return to hospital if conditions deteriorate [24]. The safety of treating PE at home, even in the non-pregnant population, is uncertain. Prediction rules have been developed for identifying nonpregnant patients with acute PE who might be suitable for outpatient treatment because they are at low risk of serious complications [24, 80].

The results of large trials in non-pregnant patients demonstrating that LMWHs are at least as safe and effective as UFH for the acute treatment of VTE [81, 82] and as vitamin $\mathrm{K}$ antagonists for the prevention of recurrent VTE $[83,84]$, as well as data from subsequent observational studies in pregnant women, support the use of LMWH for treatment of VTE in this patient population [60, 61, 85, 86].

There are no large trials examining the optimal dose of anticoagulants for treatment of acute VTE during pregnancy. Some pharmacokinetic studies suggest that increases in GFR and in patient weight (and, hence, LMWH volume of distribution) that occur during pregnancy may lead to lower LMWH levels and that the dose of LMWH should be adjusted over the course of pregnancy to maintain "therapeutic" anti-Xa LMWH levels [87, 88], or according to changes in weight [89]. However, other researchers have demonstrated that few women require dose-adjustment when therapeutic doses of LMWH are used [90-94]. Some recommend a twice-daily LMWH dosing schedule during pregnancy to compensate for increases renal clearance of this medication that occur in the second trimester. In non-pregnant patients, once daily LMWH is as safe and effective as twice daily LMWH when used to treat acute VTE [95]. Observational studies in pregnant women with acute VTE have not demonstrated any increase in the risk of recurrence with a once-daily regimen compared with twice-daily schedules $[85,86]$ and many clinicians use once-daily therapy to simplify administration and enhance compliance. 
There are issues with reliability of anti-Xa LMWH tests $[96,97]$ and these assays are costly. In the absence of robust data demonstrating that there is an optimal "therapeutic anti-Xa LMWH range" and that dose-adjustments increase the safety or efficacy of LMWH therapy, current guidelines do not mandate routine monitoring of LMWH with anti-Xa levels [21-23]. Anti-Xa monitoring may be helpful to ensure appropriate anticoagulant effect in patients with renal impairment and in those at the extremes of body weight [21].

Regimens in which the intensity of LMWH is reduced later during the course of therapy to an intermediate dose regimen [98] or $75 \%$ of a full treatment dose [84] have been used successfully in cancer patients. A recent systematic review that identified four studies in which pregnant women with symptomatic VTE were transitioned from full-dose anticoagulation to intermediate-dose LMWH (less than $75 \%$ of a full treatment dose but greater than prophylactic dose) within 6 weeks of VTE diagnosis, reported a low risk of VTE recurrence (one of 152 patients) during intermediate-dose LMWH therapy; however, the number of patients with PE was small (four) and at least one of the included studies enrolled patients with isolated calf vein thrombosis, which could lead to an overestimation of the positive effect [99]. Some guidelines suggest a dosereduction strategy for pregnant women at risk of anticoagulant-related bleeding and heparin-induced osteoporosis [23] and in those with isolated calf vein thrombosis [22]. That said, a survey of members of the North American Society of Obstetric Medicine and Thrombosis Canada found that only one-quarter of respondents utilized this strategy in their patients [100].

The risk of HIT in pregnant women treated with LMWH alone is low (less than $0.1 \%$ ) [59]; it is higher in pregnant women who have received UFH. Several guidelines suggest that routine platelet count monitoring for detection of HIT is not required in pregnant women treated exclusively with LMWH [21, 25].

Intravenous UFH is preferred when rapid reversal of anticoagulation may be required (i.e. in situations in which urgent delivery or surgery may be necessary) and in patients in whom thrombolysis may be considered (e.g. high risk or massive PE) [24, 80]. UFH should be used in preference to LMWH to treat acute VTE in patients with GFR of less than $30 \mathrm{~mL} / \mathrm{min}$ [80]. When UFH is preferred, it can be given intravenously or subcutaneously every $12 \mathrm{~h}$ in doses adjusted to prolong a mid-interval ( $6 \mathrm{~h}$ post-injection) activated partial thromboplastin time (aPTT) into therapeutic range [101], although it is recognized that aPTT monitoring is less reliable in pregnancy [102].
Concerns about the use of thrombolytic therapy during pregnancy center on its maternal effects (major hemorrhage), as well as those on the placenta (i.e. premature labor, placental abruption, fetal demise), as transplacental passage of tissue plasminogen activator and streptokinase is minimal [103]. There have been several reports of successful thrombolysis in pregnancy with no harm to the fetus; however, the number of cases is small and most cases involved streptokinase [104-107]. Therefore, there is agreement amongst available guidelines that the use of thrombolytic therapy in pregnancy is best reserved for limb or life-threatening maternal thromboembolism (e.g. PE with refractory cardiorespiratory compromise) [21-23, 80].

There is limited experience with inferior vena caval filters during pregnancy and serious complications, including filter fracture, filter migration, failed retrieval of temporary devices, and inferior vena caval perforation, have been reported [108-112]. Current guidelines recommend insertion of temporary inferior vena caval filters in pregnant women with acute VTE and contraindications to anticoagulant therapy $[18,22]$ or recurrent VTE despite therapeutic anticoagulation [17, 21-23]. An alternate strategy involving anticoagulant dose-escalation may also be appropriate for managing the latter situation, based on favorable (but limited) data in cancer patients, in which recurrent VTE despite anticoagulant therapy is treated by increasing the dose of LMWH by approximately $25 \%$ or to therapeutic levels in those receiving lower doses [113, 114].

There are conflicting data concerning the long-term effectiveness of graduated compression stockings to prevent post-thrombotic syndrome. On the basis of two positive open label randomized trials in the non-pregnant population [115, 116], several guidelines have suggested that graduated compression stockings be prescribed to reduce the likelihood of developing post-thrombotic syndrome [19, 22, 23]. However, a recent multicenter placebocontrolled trial that enrolled non-pregnant patients reported that these stockings neither prevented this complication nor reduced the risk of recurrent VTE [117]. In addition, although it is thought that graduated stockings may be useful for acute symptom relief, a subgroup analysis of this study suggests that, at least in the non-pregnant population, this may not be the case [118].

There have been no studies assessing optimal duration of anticoagulant therapy for treatment of pregnancy-related VTE. In non-pregnant patients with VTE, evidence supports a minimum treatment duration of 3 months [24]. Given the increased risk of VTE in pregnant women and following delivery, available guidelines suggest that 
anticoagulants be continued throughout pregnancy and the postpartum period, and for a minimum of 3 months [19, 21-25].

\section{Guidance Statement}

- Outpatient treatment of VTE can be considered in patients who are clinically stable and have good cardiorespiratory reserve, no major risk factors for bleeding and good social support with easy access to medical care. Hospitalization is indicated in patients who are hemodynamically unstable or do not have good social support and those who have extensive VTE, or maternal co-morbidities that limit their tolerance of recurrent VTE or increase their risk of major bleeding.

- LMWH is the preferred anticoagulant for most pregnant women with acute VTE. UFH should be used instead of LMWH in patients with GFR less than $30 \mathrm{~mL} / \mathrm{min}$. Intravenous UFH should be considered in patients who may require thrombolysis, surgery or urgent delivery.

- If LMWH is used for treatment of acute VTE in pregnancy, the same weight-adjusted dosing regimen as in the nonpregnant population should be utilized (Table 3). Routine monitoring of LMWH dosing with anti-Xa LMWH is likely not required.

- Thrombolytic therapy should be reserved for pregnant women with PE associated with life-threatening cardiorespiratory compromise or limb-threatening DVT.

- Insertion of a temporary inferior vena caval filter should be considered in pregnant women with acute VTE and a contraindication to anticoagulant therapy.

- Anticoagulant therapy for treatment of VTE during pregnancy should be continued throughout pregnancy and for at least 6 weeks postpartum for a minimum duration of 3 months.

4. How is pregnancy-associated VTE prevented?

Decisions regarding the use of prophylactic anticoagulation during pregnancy depend on the balance between the estimated risk of VTE and associated reduction in risk with prophylaxis, along with the burdens associated with anticoagulant therapy. The appropriate use of prophylaxis depends on identifying those at sufficiently high risk of VTE to benefit from this intervention. Risk factors to be considered include prior VTE, familial VTE history, the presence of a known thrombophilia, and clinical factors, including cesarean delivery, prolonged antepartum immobilization, increased body mass index (BMI), as well as significant pregnancy complications and medical comorbidities.

Prophylaxis during pregnancy typically involves longterm subcutaneous injections of LMWH. Although prophylactic LMWH is safe for the fetus [27, 29, 30, 49-51] and does not appear to appreciably increase the risk of adverse maternal outcomes [58, 59, 62-67]; it is expensive, inconvenient and uncomfortable to administer. Depending on local practice, prophylaxis with LMWH may also necessitate a planned delivery to permit epidural analgesia and women may perceive that it creates an undesirable "medicalization" of their pregnancy.

A Cochrane systematic review of thromboprophylaxis in pregnancy and the early postnatal period that examined 16 randomized trials involving 2592 women concluded that the current available information is insufficient to make firm recommendations for prophylaxis [119]. Current clinical guidelines are based on these small trials, additional observational studies and indirect evidence suggesting that LMWH substantially decreases the risk of VTE in a wide variety of clinical settings. As shown in Table 2C, there is incomplete agreement between the guidelines as to which patients should receive thrombosis prophylaxis and only a few guidelines (SOGC [19] and ACCP for postpartum prophylaxis [23]) explicitly provide information about the risk threshold used to determine whether or not patients should receive prophylaxis.

Given the competing potential drawbacks and benefits of prophylaxis, as well as the limitations of the available evidence, the decision to use or not use LMWH is likely to be value and preference sensitive. In addition to holding different attitudes toward the risk of recurrent thrombosis and about the burdens associated with the use of prophylaxis, women are also likely to place varying importance on minimizing medicalization of their pregnancy. All women, therefore, merit an individualized risk-benefit assessment of their need for prophylaxis and the opportunity to share in

Table 3 Accepted LMWH dosing regimens for treatment of pregnancy-related VTE

\begin{tabular}{|c|c|}
\hline \multirow{5}{*}{$\begin{array}{l}\text { Initial } \\
\text { treatment }\end{array}$} & Therapeutic (adjusted-dose) LMWH \\
\hline & Dalteparin 200 units/kg once daily or 100 units/kg every $12 \mathrm{~h}$ \\
\hline & Tinzaparin 175 units/kg once daily \\
\hline & Enoxaparin $1 \mathrm{mg} / \mathrm{kg}$ every $12 \mathrm{~h}$ \\
\hline & Nadroparin 86 units/kgevery 12 h or 171 units/kg once daily \\
\hline \multirow{2}{*}{$\begin{array}{l}\text { Dose } \\
\text { adjustments }\end{array}$} & No dose adjustment \\
\hline & $\begin{array}{l}\text { For patients at risk for bleeding or osteoporosis and for those with isolated distal DVT, consideration can be given to } \\
\text { decreasing the dose to } 75 \% \text { of full treatment dose after at least a month of therapy }\end{array}$ \\
\hline
\end{tabular}


a decision making process about this intervention that takes into account their values and preferences.

If the decision is made to use antepartum prophylaxis, it should be initiated early in pregnancy as there is evidence of an increased risk of VTE during all three trimesters $[120,121]$. Postpartum prophylaxis is less burdensome than antepartum prophylaxis as the duration of prophylaxis is shorter (i.e. 6 weeks) and an oral anticoagulant is available for those uncomfortable with subcutaneous injections (vitamin $\mathrm{K}$ antagonists, except for those with protein $\mathrm{C}$ or $\mathrm{S}$ deficiency who are at risk for developing warfarin-induced skin necrosis) [122-124].

The optimal prophylaxis strategy is unknown. Several LMWH dosing regimens have been used for prophylaxis of VTE during pregnancy (Table 4) [59, 62, 118, 125-133]. Although all of the studies evaluating these regimens reported low VTE rates, most were cohort studies and, therefore, lacked data from untreated controls. Some investigators have reported failures of prophylactic LMWH; however, it is unclear whether these represent true failures or were due to noncompliance with long-term subcutaneous injections [59, 60, 127, 134, 135]. Different dosing strategies have not been directly compared, although one randomized trial comparing higher doses of LMWH prophylaxis with usual fixed dose prophylaxis is ongoing (Highlow Randomized Controlled Trial: Comparison of Low and Intermediate Dose Low-molecularweight Heparin to Prevent Recurrent Venous Thromboembolism in Pregnancy; NCT001828697).

In hospitalized women, mechanical prophylaxis with elastic stockings and/or intermittent pneumatic compression is an alternative for those with contraindications to anticoagulant prophylaxis [23]; although there is limited evidence that these devices are less effective at prevention of VTE [136].

Duration of anticoagulant prophylaxis after delivery remains controversial. Available guidelines recommend 6 weeks of postpartum prophylaxis in patients with prior

Table 4 Suggested LMWH dosing regimens for prophylaxis against pregnancy-related VTE

Prophylactic $\mathrm{LMWH}^{\mathrm{a}}$
Dalteparin 5000 units once daily
Tinzaparin 4500 units once daily or 75 units/kg once daily
Enoxaparin $40 \mathrm{mg}$ once daily
Nadroparin 2850 units once daily
Intermediate-dose $\mathrm{LMWH}^{\mathrm{a}}$
Dalteparin 5000 units twice daily or 10,000 units once daily
Tinzaparin 10,000 units once daily
Enoxaparin $40 \mathrm{mg}$ twice daily or $80 \mathrm{mg}$ once daily
LMWH adjusted to a peak anti-Xa level of $0.2-0.6$ units $/ \mathrm{mL}$

${ }^{a}$ Higher doses may be used in with increased maternal weight
VTE and those with some thrombophilias (varies between guidelines) [17, 19, 21, 23]. However, there is minimal evidence to guide duration of prophylaxis in women with other clinical risk factors and recommendations vary. A shorter course of postpartum prophylaxis (until discharge or for one to 2 weeks post discharge) is often suggested for women with transient risk factors [19, 21, 23]. A recent study that used linked primary and secondary care data to assess VTE risk during specific postpartum periods reported that women with pre-eclampsia/eclampsia and acute systemic infection, obesity (body mass index or BMI $\geq$ $30 \mathrm{~kg} / \mathrm{m}^{2}$ ), and cesarean delivery had elevated VTE risks up to 6 weeks postpartum; while VTE risk was increased only for the first 3 weeks after delivery in those with postpartum hemorrhage or preterm birth [137]. However, the absolute VTE risk during those time frames was low (less than $1 \%$ ).

All pregnant women at risk of VTE should be educated about the signs and symptoms of DVT and PE and the need to seek urgent medical attention should they develop. Objective testing is mandatory if symptoms suspicious of DVT or PE occur.

\section{Prevention of recurrent VTE}

The most important individual risk factor for pregnancyassociated VTE is a prior history of thrombosis [138]. The absolute risk of recurrent VTE during pregnancy in women not given antepartum prophylaxis remains controversial. In more recent studies, the reported incidence ranged from $2.4 \%$ (95\% CI 0.2-6.9) in a prospective study of 125 pregnant women [139] to approximately $6 \%$ in larger retrospective cohort studies [140, 141]. Differences in study population (later median gestational age at enrollment; inclusion of women with more than one prior episode of VTE in the retrospective studies), as well as failure to independently adjudicate recurrent events in the retrospective studies, may explain the higher risk of recurrence in the latter studies. However, the overall risk of antepartum recurrent VTE in both prospective and retrospective studies was less than $10 \%$ and CI's around the risk estimates of individual studies are overlapping.

Data regarding prognostic factors for recurrent VTE during pregnancy are inconsistent. Although a subgroup analysis of the prospective cohort study mentioned above found a lower risk of recurrence in women without thrombophilia who had a temporary risk factor (including oral contraceptive therapy or pregnancy) at the time of their prior VTE, than in those with abnormal thrombophilia testing and/or an unprovoked event [138]; in the two subsequent retrospective studies, the presence or absence of a definable thrombophilia did not appear to influence the risk of recurrent pregnancy-associated VTE [140, 141]. Studies in nonpregnant patients have also demonstrated that 
thrombophilic abnormalities do not play an important role in determining the risk of recurrent VTE, despite being clear risk factors for a first episode of DVT or PE [142]. There was a suggestion in the two retrospective studies that women with a first VTE provoked by oral contraceptives or related to pregnancy might be at higher risk of recurrence in a subsequent pregnancy than those with an unprovoked event or VTE related to a transient non-hormonal risk factor [140, 141]. The latter findings are consistent with those from an observational administrative dataset from California [143].

The above data suggest that pregnant women with a single prior episode of VTE associated with a transient risk factor not related to pregnancy or use of estrogen are likely at lower risk of recurrent antepartum VTE compared to pregnant women with a history of unprovoked, pregnancy or estrogen-related VTE. The ACCP guidelines estimated the risk of recurrent antepartum VTE without prophylaxis to be $2 \%$ in the first group and $8 \%$ in the second group [23]. Current guidelines favor a strategy of antepartum clinical vigilance for those with a single prior episode of VTE associated with a transient risk factor not related to pregnancy or hormone use and antepartum LMWH with a history of unprovoked, pregnancy or estrogen-related VTE $[17,19,20,23]$. However, as the available data have significant limitations, antepartum clinical vigilance may also acceptable for higher risk patients accepting of the risks of recurrence and for whom the burden of LMWH prophylaxis outweighs potential benefits. Similarly, women with a prior VTE associated with a transient risk factor not related to pregnancy or use of estrogen may benefit from antepartum prophylaxis if they have additional major risk factors for thrombosis. Although supportive data from clinical trials are lacking, postpartum prophylaxis for 6 weeks with prophylactic or intermediate dose LMWH or vitamin $\mathrm{K}$ antagonists targeted at INR 2.0-3.0 is generally recommended for all pregnant women with prior VTE not receiving long-term anticoagulants $[17,19,20,23]$.

\section{Prevention of VTE in pregnant women with thrombophilia and no prior VTE}

Thrombophilias are laboratory abnormalities associated with an increased risk of thrombosis and can be either inherited or acquired. The majority of studies that have examined the risk of VTE in pregnancy have focused on inherited thrombophilic mutations. Although it has been reported that approximately $50 \%$ of pregnancy-associated VTE are associated with inherited thrombophilia; these abnormalities are very common and collectively are present in at least $15 \%$ of the population [144, 145].

As shown in Table 5, in a systematic review of nine case control studies $(n=2526)$ that evaluated the association between thrombophilia and pregnancy-associated VTE, the highest risks were associated with homozygosity for factor V Leiden or the prothrombin G20210A variant [146]. Pregnant women with the most common heritable thrombophilias (i.e. heterozygosity for factor $\mathrm{V}$ Leiden or the prothrombin G20210A variant) had lower risks. Deficiencies of antithrombin, protein $\mathrm{C}$, and protein $\mathrm{S}$ were associated with moderate risk increases. Estimated absolute VTE risks, calculated using the provided odds ratios and a background incidence of VTE during pregnancy of approximately $1 / 1000$ deliveries, suggest a low thrombosis risk (0.5-1.2\% of affected pregnancies) for most of the inherited thrombophilias, except perhaps for homozygous carriers of the factor $\mathrm{V}$ Leiden or the prothrombin mutations, where the risk estimate is approximately $4 \%$ (Table 5 ). However, these findings are limited by the fact that most of the included women would not have had a family history of VTE. A positive family history of VTE increases the risk for VTE two- to four-fold, depending on the number of affected relatives $[147,148]$ and thrombophilic subjects without a personal or family history of DVT or PE have lower rates of VTE than patients with thrombophilia and a positive family history [149]. Family-based cohort studies not included in the above-mentioned systematic review suggest that the risks of developing a first VTE during pregnancy and the postpartum period are two to four times greater than estimated in thrombophilic women without a positive family history (Table 5) [150-161]. However, it should be noted that many of the events occurred during the postpartum period and these risk estimates are very imprecise, particularly for the less common thrombophilias.

Acquired thrombophilias have been less well studied but repeated antiphospholipid antibody positivity (lupus anticoagulants [non-specific inhibitors], anticardiolipin antibodies, or anti- $\beta 2$ glycoprotein-I antibodies) is associated with an increased risk of VTE [162]. The risk or pregnancy-related VTE in women with antiphospholipid antibodies and no previous history of venous thrombosis is uncertain [163, 164].

There is considerable disagreement between current guidelines about the indication for antepartum thrombosis prophylaxis in pregnant women with deficiencies of antithrombin, protein $\mathrm{C}$, or protein $\mathrm{S}$. The inconsistency in recommendations likely results from the use of different risk thresholds for suggesting prophylaxis, uncertainty in risk estimates in recent studies, as described above, and concerns about VTE risks presented in older studies that suggested that these are high risk thrombophilias [165167]. However, this data is somewhat problematic as these papers have methodologic limitations, including acceptance of non-objectively diagnosed outcome events, failure to clearly specify criteria for the diagnosis of VTE, including recurrent VTE episodes in women who already 
Table 5 Risks of pregnancy-related VTE in asymptomatic thrombophilic women

\begin{tabular}{|c|c|c|}
\hline Thrombophilia & Estimated relative risk OR $(95 \% \mathrm{CI})^{\mathrm{a}}$ & $\begin{array}{l}\text { Estimated absolute risk of } \\
\text { VTE \% of pregnancies } \\
\text { (antepartum and postpartum) }(95 \% \mathrm{CI})\end{array}$ \\
\hline \multicolumn{3}{|c|}{ Antithrombin, protein $\mathrm{C}$ or protein $\mathrm{S}$ deficiency } \\
\hline \multirow[t]{3}{*}{ Family studies } & & $4.1(1.6-8.3)^{\mathrm{b}}$ \\
\hline & & $3.2(0.5-16.2)(\text { total })^{\mathrm{c}}$ \\
\hline & & $8.3(1.5-35.4)$ (no prophylaxis) $^{\mathrm{c}}$ \\
\hline \multicolumn{3}{|l|}{ Antithrombin deficiency } \\
\hline Non-family studies & $4.7(1.3-17.0)$ & $0.7(0.2-2.4)^{\mathrm{a}}$ \\
\hline \multirow[t]{3}{*}{ Family studies } & & $3.0(0.08-15.8)^{\mathrm{b}}$ \\
\hline & & $8.3(1.4-35.4)(\text { total })^{\mathrm{c}}$ \\
\hline & & $14.3(2.6-51.3)(\text { no prophylaxis) })^{\mathrm{c}}$ \\
\hline \multicolumn{3}{|l|}{ Protein $\mathrm{C}$ deficiency } \\
\hline Non-family studies & $4.8(2.2-10.6)$ & $0.7(0.3-1.5)^{\mathrm{a}}$ \\
\hline \multirow[t]{3}{*}{ Family studies } & & $1.7(0.4-8.9)^{\mathrm{b}}$ \\
\hline & & $0(0-25.9)(\text { total })^{\mathrm{c}}$ \\
\hline & & $0(0-79.4)$ (no prophylaxis) ${ }^{\mathrm{c}}$ \\
\hline \multicolumn{3}{|l|}{ Protein S deficiency } \\
\hline Non-family studies & $3.2(1.5-6.9)$ & $0.5(0.2-1.0)^{\mathrm{a}}$ \\
\hline \multirow[t]{3}{*}{ Family studies } & & $6.6(2.2-14.7)^{\mathrm{b}}$ \\
\hline & & $0(0-32.4)(\text { total })^{\mathrm{c}}$ \\
\hline & & $0(0-48.9)$ (no prophylaxis) ${ }^{\mathrm{c}}$ \\
\hline \multicolumn{3}{|l|}{ Factor V Leiden, heterozygous } \\
\hline Non-family studies & $8.3(5.4-12.7)$ & $1.2(0.8-1.8)^{\mathrm{a}}$ \\
\hline Family studies & & $3.1(2.1-4.6)^{\mathrm{d}}$ \\
\hline \multicolumn{3}{|l|}{ Factor V Leiden, homozygous } \\
\hline Non-family studies & $34.4(9.9-120.1)$ & $4.8(1.4-16.8)^{\mathrm{a}}$ \\
\hline Family studies & & $14.0(6.3-25.8)^{\mathrm{e}}$ \\
\hline \multicolumn{3}{|c|}{ Prothrombin G20201A, heterozygous } \\
\hline Non-family studies & $6.8(2.5-18.8)$ & $1.0(0.3-2.6)^{\mathrm{a}}$ \\
\hline Family studies & & $2.6(0.9-5.6)^{\mathrm{f}}$ \\
\hline \multicolumn{3}{|c|}{ Prothrombin G20201A, homozygous } \\
\hline Non family history of studies & $26.4(1.2-559.3)$ & $3.7(0.2-78.3)^{\mathrm{a}}$ \\
\hline
\end{tabular}

${ }^{a}$ Estimated absolute risks are derived by multiplying the pooled odds ratios with their corresponding $95 \%$ CIs from Robertson et al. [146] with the overall baseline VTE incidence (i.e. antepartum and until 6 weeks postpartum combined) of 1.4 per 1000 [23]

${ }^{\mathrm{b}}$ Data from Friederich et al. [160]

c Data from Mahmoodi et al. [151]

d Data from Middeldorp et al. [152], Simioni et al. [156], Middeldorp et al. [157], Simioni et al. [158], Couturaud et al. [159]

e Data from Middeldorp et al. [152], Martinelli et al. [153], Tormene et al. [153]

${ }^{\mathrm{f}}$ Data from Bank et al. [160], and Coppens et al. [161]

had had a VTE, and the potential for referral and recall bias, that have the potential to lead to an overestimation of risk.

Prevention of pregnancy-associated VTE in patients with clinical risk factors

Most studies that have assessed clinical and pregnancyrelated risk factors for VTE have utilized a case control or cross-sectional design (Table 6) [3-5, 7, 87, 168-170]; although a few recent publications have used large databases to provide population-level absolute and relative risks for VTE [171, 172]. In methodologically stronger studies, most established risk factors have only a modest effect on VTE risk, with few increasing the absolute risk about $1 \%$. How combinations of independent risk factors might affect overall VTE risk has not been extensively studied and in most cases, it is unclear whether 
Table 6 Clinical risk factors for VTE as determined from case-control or cross-sectional studies

\begin{tabular}{|c|c|c|}
\hline Risk factor & $\begin{array}{l}\text { Adjusted OR/ } \\
\text { HR }\end{array}$ & $95 \% \mathrm{CI}$ \\
\hline \multicolumn{3}{|l|}{ Antepartum risk } \\
\hline Immobility (strict bedrest for $\geq 1$ week in the antepartum period) with pre-pregnancy BMI $\geq 25 \mathrm{~kg} / \mathrm{m}^{2}$ & 62.3 & $11.5-337.0$ \\
\hline Immobility (strict bedrest for $\geq 1$ week in the antepartum period) with pre-pregnancy BMI $<25 \mathrm{~kg} / \mathrm{m}^{2}$ & 7.7 & $3.2-19.0$ \\
\hline Assisted reproductive techniques-first trimester & 4.6 & $2.9-7.2$ \\
\hline Spontaneous twins & 2.6 & $1.1-6.2$ \\
\hline Antepartum hemorrhage & 2.3 & $1.8-2.8$ \\
\hline Smoking (10-30 cigarettes/d prior to or during pregnancy) & 2.1 & $1.3-3.4$ \\
\hline Pre-pregnancy BMI $\geq 25 \mathrm{~kg} / \mathrm{m}^{2}$ —no immobilization & 1.8 & $1.3-2.4$ \\
\hline Weight gain $<7.0 \mathrm{~kg}$ & 1.7 & $1.1-2.6$ \\
\hline \multicolumn{3}{|l|}{ Postpartum risk } \\
\hline Immobility (strict bedrest for $\geq 1$ week in the antepartum period) with pre-pregnancy BMI $\geq 25 \mathrm{~kg} / \mathrm{m}^{2}$ & 40.1 & $8.0-201.5$ \\
\hline $\begin{array}{l}\text { Postpartum infection (clinical signs/symptoms with fever and elevated white blood cell count) following } \\
\text { vaginal delivery }\end{array}$ & 20.2 & $6.4-63.5$ \\
\hline $\begin{array}{l}\text { Postpartum hemorrhage } \geq 1000 \mathrm{~mL} \text { with surgery (curettage, evacuation of hematoma, or re-operation after } \\
\text { cesarean section) }\end{array}$ & 12.0 & $3.9-36.9$ \\
\hline Immobility (strict bedrest for $\geq 1$ week in the antepartum period) with pre-pregnancy BMI $<25 \mathrm{~kg} / \mathrm{m}^{2}$ & 10.8 & $4.0-28.8$ \\
\hline $\begin{array}{l}\text { Postpartum infection (clinical signs/symptoms with fever and elevated white blood cell count) following } \\
\text { cesarean section }\end{array}$ & 6.2 & $2.4-16.2$ \\
\hline Pre-eclampsia with fetal growth restriction & 5.8 & $2.1-16.0$ \\
\hline Postpartum hemorrhage $>1000 \mathrm{~mL}$ with no surgery & 4.1 & $2.3-7.3$ \\
\hline Fetal growth restriction (gestational age + sex-adjusted birth weight $<2.5$ th percentile) & 3.8 & $1.4-10.2$ \\
\hline Smoking (10-30 cigarettes/d prior to or during pregnancy) & 3.4 & $2.0-4.4$ \\
\hline Pre-eclampsia & 3.1 & $1.8-5.3$ \\
\hline Hyperemesis & 2.5 & $2.0-3.2$ \\
\hline Pre-pregnancy BMI $<25 \mathrm{~kg} / \mathrm{m}^{2}$ —no immobilization & 2.4 & $1.7-3.3$ \\
\hline Smoking (5-9 cigarettes/d prior to or during pregnancy) & 2.0 & $1.1-3.7$ \\
\hline Pre-pregnancy $>25 \mathrm{~kg} / \mathrm{m}^{2}$-no immobilization & 1.8 & $1.3-2.4$ \\
\hline \multicolumn{3}{|l|}{ Risk period not specified } \\
\hline Systemic lupus erythematosus & 8.7 & $5.8-13.0$ \\
\hline Blood transfusion & 7.6 & $6.2-9.4$ \\
\hline Heart disease & 7.1 & $6.2-8.3$ \\
\hline Sickle cell disease & 6.7 & $4.4-10.1$ \\
\hline Multiple pregnancy & 4.2 & $1.8-9.7$ \\
\hline $\mathrm{BMI} \geq 30 \mathrm{~kg} / \mathrm{m}^{2}$ & 5.3 & $2.1-13.5$ \\
\hline Assisted reproductive techniques & 1.8 & $1.4-2.3$ \\
\hline Anemia & 2.6 & $2.2-2.9$ \\
\hline Diabetes & 2.0 & $1.4-2.7$ \\
\hline Hypertension & 1.8 & $1.4-2.3$ \\
\hline Weight gain >21 kg (vs. 7-21 kg) & 1.6 & $1.1-2.6$ \\
\hline Parity $>1$ & 1.5 & $1.1-1.9$ \\
\hline
\end{tabular}

Data from: Lindqvist et al. [3], Simpson et al. [4], James et al. [5], Jacobsen et al. [7], Knight et al. [86], Henriksson et al. [168], Jacobsen et al. [169]

BMI body mass index 
combinations result in additive or multiplicative risks. Further research in this area is required.

Prevention of pregnancy-associated VTE following cesarean delivery

Several observational studies have assessed the risk of VTE after cesarean delivery. Small prospective studies in which patients underwent screening ultrasounds following cesarean section and were then followed post-discharge for at least 6 weeks reported symptomatic VTE event rates of 0 (95\% CI 0-6.1\%) [173] and $0.5 \%$ (95\% CI 0.1-2.8\%) [174]. The latter is consistent with estimates based on hospital discharge data that antedate the use of thrombosis prophylaxis [1, 175]. Emergency cesarean delivery approximately doubles the risk of VTE [7, 169, 172].

In the Cochrane systematic review mentioned above, four ( 840 women) of the nine included trials that examined prophylaxis following cesarean delivery compared heparin (UFH or LMWH) with placebo [119]. There was no evidence that using any form of heparin following delivery reduced the risk of maternal VTE (risk ratio [RR] vs no heparin for symptomatic events of $1.30 ; 95 \%$ CI $0.39-4.27$ ) and the authors concluded there was insufficient evidence on which to base recommendations.

Guidance Statement Note: Given the uncertainty around optimal prophylactic strategies, all women should be provided with the opportunity to participate in shared decision making regarding this intervention, including a discussion of VTE risks, potential benefits (reduction in VTE risk) and drawbacks (risks of bleeding and localized skin reactions; cost; potential limitation of analgesic options at the time of delivery; anxiety associated with injections) of prophylaxis along with their values and preferences. Physicians and patients (and, perhaps, societies) with a lower threshold for recurrent VTE may choose a more aggressive anticoagulant strategy than recommended, whereas withholding prophylaxis may be appropriate in those who are willing to accept a higher risk of recurrence in order to forgo the drawbacks associated with prophylaxis.

\section{General Comments}

- All pregnant women at risk of VTE should be educated about the signs and symptoms of DVT and PE and the need to seek urgent medical attention should they develop. Objective testing is mandatory if symptoms suspicious of DVT or PE occur.

- All women should undergo an individualized risk assessment for VTE prior to pregnancy, once pregnancy is achieved and throughout pregnancy as new clinical situations arise.
- When considering the use of thrombosis prophylaxis during pregnancy and/or the postpartum period, the absolute risk of VTE, the risk reduction with prophylaxis, drawbacks of prophylaxis, and the woman's values and preferences should all be taken into account. Given the limitations of the available data, clinical vigilance rather than prophylaxis may also be acceptable for patients accepting the VTE risks quoted above and for whom the burden of LMWH prophylaxis outweighs potential benefits.

- If the decision is made to use antepartum prophylaxis, it should be initiated early in pregnancy.

- Six weeks of postpartum prophylaxis is recommended in patients with prior VTE and those with some thrombophilias. A shorter course of postpartum prophylaxis (until discharge or for 1-2 weeks post discharge) is suggested for women with transient risk factors.

\section{Prevention of recurrent VTE}

- Pregnant women with prior VTE who are not receiving long-term anticoagulation should receive 6 weeks of postpartum prophylaxis.

- Antepartum prophylaxis should be considered in pregnant women with prior unprovoked VTE or pregnancyor estrogen-related VTE not receiving long-term anticoagulation.

Prevention of VTE in women with thrombophilia and no prior VTE

- Asymptomatic women who are homozygous for the factor $V$ Leiden mutation or prothrombin gene mutation and who have a family history of VTE should receive antepartum and postpartum prophylaxis.

- Consideration should be given to providing postpartum prophylaxis in asymptomatic women who are heterozygous for the factor $V$ Leiden mutation or prothrombin gene mutation or who have protein $C$ or protein $S$ deficiency and who have a family history of VTE.

- Given the variability in the VTE risk estimates for asymptomatic women with antithrombin deficiency and a family history of VTE, either a strategy of antepartum and postpartum prophylaxis or postpartum prophylaxis alone is reasonable.

- Asymptomatic women who are homozygous for the factor $V$ Leiden mutation or prothrombin gene mutation and who have no family history of VTE should receive postpartum prophylaxis.

- Asymptomatic women with all other thrombophilias who do not have a family history of VTE do not require prophylaxis, in the absence of other risk factors. However, given the variability in the VTE risk estimates for asymptomatic women with antithrombin deficiency 
and no family history of VTE, consideration could also be given to utilizing postpartum prophylaxis in these patients.

\section{Prevention of VTE in women with clinical risk factors}

- Antepartum prophylaxis should be provided to immobilized (strict bedrest) women with a pre-pregnancy BMI of at least $25 \mathrm{~kg} / \mathrm{m}^{2}$ and to those with a prior history of VTE regardless of their BMI. Consideration should be given to providing prophylaxis during antepartum immobilization (as defined above) to women with a lower body mass index who have other significant comorbidities (e.g. systemic lupus erythematosus, sickle cell disease, heart disease) associated with an increased risk of VTE or a thrombophilia.

- Consideration should be given to providing postpartum prophylaxis while in hospital to women with a history of antepartum immobilization (as defined above) for at least 7 days and to those who are immobilized postpartum who have a known thrombophilia or significant medical comorbidity

\section{Prevention of VTE in after cesarean delivery}

- Prophylaxis should be provided after cesarean delivery to women with the following risk factors:

One or more of prior VTE, a history of antepartum immobilization (strict bedrest for at least 1 week), significant postpartum infection, postpartum hemorrhage of at least $1000 \mathrm{~mL}$ requiring re-operation, pre-eclampsia with growth restriction, significant medical co-morbidities (systemic lupus erythematosis, heart disease, or sickle cell disease) or a known thrombophilia.

Two or more of (or one or more in the setting of emergency cesarean delivery) of postpartum hemorrhage of at least $1000 \mathrm{~mL}$ that does not require reoperation, BMI $>30 \mathrm{~kg} / \mathrm{m}^{2}$, fetal growth restriction, pre-eclampsia, multiple pregnancy and tobacco use during pregnancy (at least 10 cigarettes per day)

5. How is peripartum anticoagulation managed?

The delivery options in women using anticoagulants are best considered by a multidisciplinary team in order to minimize the risks of maternal hemorrhage, epidural hematoma, and VTE around the time of delivery. In a systematic review of 2777 pregnancies in which LMWH was utilized in either therapeutic or prophylactic doses, postpartum hemorrhage of greater than $500 \mathrm{~mL}$ occurred in 26 pregnancies $(0.94 \%$; $95 \%$ CI $0.61-1.37 \%$ ) and wound hematoma in 17 pregnancies $(0.61 \%, 95 \%$ CI 0.36-0.98\%) [59]. A more recent systematic review of 18 studies that focused solely on pregnant women $(n=981)$ receiving treatment for acute VTE during pregnancy reported an incidence of major bleeding during the first $24 \mathrm{~h}$ after delivery of $1.90 \%(95 \% \mathrm{CI}$ 0.80-3.60\%) [60]. Although epidural hematomas in obstetrical patients receiving epidural analgesia/anesthesia are rare, with an estimated incidence of less than 1 in 150,000 [176]; the potential complications are devastating and include permanent neurologic dysfunction.

Depending on local practice, delivery options include spontaneous labor and delivery, induction of labor, and planned cesarean delivery. Induction of labor may help to avoid an unwanted anticoagulant effect during delivery (especially with neuroaxial anesthesia) in women receiving LMWH. Current guideline recommendations for management of anticoagulant therapy around the time of delivery are outlined in Table 2D. Anesthesia and obstetrical guidelines agree that $24 \mathrm{~h}$ should pass between the last dose of therapeutic LMWH and insertion of a neuroaxial catheter [17, 19-23, 177]. For prophylactic LMWH, catheter insertion should occur no sooner than 10-12 h after the last LMWH dose [17, 19-23, 177].

At some centers, women are converted from therapeutic adjusted-dose LMWH to subcutaneous twice daily therapeutic dose UFH in the last month of pregnancy. However, therapeutic doses of subcutaneous UFH may cause a persistent anticoagulant effect. One study reported that six of 11 women receiving subcutaneous UFH during pregnancy had an elevated aPTT at delivery despite discontinuing their injections at the onset of labour to $12 \mathrm{~h}$ prior to elective induction [178].

Patients should be instructed to withhold their injections if they believe that they have entered labor spontaneously. In centers with laboratory support that allows for rapid assessment of heparin levels, testing can be considered to guide anesthetic and surgical management; otherwise time since last injection should be used. If anticoagulation precludes regional techniques, alternative analgesic options include intravenous analgesia or general anesthesia for cesarean delivery [20-22].

The potential increased risk of wound hematoma after cesarean delivery in patients receiving anticoagulant therapy has led to the suggestion that wound drains and closure techniques that allow easy hematoma drainage be considered in this population [179]. If bleeding occurs that is considered secondary to LMWH rather than an obstetric cause, protamine sulfate may provide partial neutralization [180].

Women diagnosed with proximal DVT or PE within two to 4 weeks of delivery are at very high risk for recurrent VTE with prolonged anticoagulant cessation [181, 182]. A strategy involving planned delivery with transition to intravenous UFH will minimize time off 
Table 7 Summary of guidance statements

Question Guidance statement

1. What are the risks of anticoagulant use during pregnancy?

2. What are the risks of anticoagulation in breastfeeding women?

3. How is venous thromboembolism during pregnancy treated?
Physicians should counsel women receiving long-term therapy with vitamin $\mathrm{K}$ antagonists and the oral direct-acting anticoagulants about the fetal risks of these medications before pregnancy occurs

LMWH is the drug of choice for treatment and prevention of VTE in pregnancy, except in patients with HIT, a history of HIT, or significant renal dysfunction. UFH is preferred in patients with significant renal dysfunction

For women taking vitamin $\mathrm{K}$ antagonists, two options are available to reduce the risk of warfarin embryopathy. The first is to advise women to perform frequent pregnancy tests and substitute LMWH for warfarin once pregnancy is achieved and before 6 weeks gestation. Alternatively, LMWH or UFH can be substituted for vitamin $\mathrm{K}$ antagonists before conception is attempted

Although the latter approach minimizes the risks of early miscarriage associated with vitamin $\mathrm{K}$ antagonist therapy, it lengthens the duration of exposure to LMWH or UFH and, therefore, is costly and exposes the patient to a greater burden of treatment associated with the use of injectable heparin therapy. Since warfarin embryopathy is unlikely to result from warfarin exposure before 6 weeks, the first option is usually favored by guidelines. Although the management of women who are receiving long-term therapy with oral direct thrombin and factor Xa inhibitors and attempting to conceive remains controversial, it has been suggested that these women should be converted to a coumarin or LMWH before conception is attempted; failing that, the switch should be made as soon as pregnancy is confirmed

In pregnant women with severe cutaneous allergies to UFH or LMWH or with HIT or a history of HIT, danaparoid or fondaparinux (if danaparoid not available) may be used. Appropriate dosage and management of these anticoagulants around the time of delivery should be discussed with a hematologist or thrombosis specialist

UFH, LMWH, warfarin and acenocoumarol are safe for the breast-fed infant when administered to the nursing mother

The oral direct thrombin and factor Xa inhibitors should not be used while breastfeeding

Outpatient treatment of VTE can be considered in patients who are clinically stable and have good cardiorespiratory reserve, no major risk factors for bleeding and good social support with easy access to medical care. Hospitalization is indicated in patients who are hemodynamically unstable or do not have good social support and those who have extensive VTE, or maternal co-morbidities that limit their tolerance of recurrent VTE or increase their risk of major bleeding

LMWH is the preferred anticoagulant for most pregnant women with acute VTE. UFH should be used instead of LMWH in patients with GFR less than $30 \mathrm{~mL} / \mathrm{min}$. Intravenous UFH should be considered in patients who may require thrombolysis, surgery or urgent delivery

If LMWH is used for treatment of acute VTE in pregnancy, the same weightadjusted dosing regimen as in the nonpregnant population should be utilized (Table 3). Routine monitoring of LMWH dosing with anti-Xa LMWH is likely not required

Thrombolytic therapy should be reserved for pregnant women with PE associated with life-threatening cardiorespiratory compromise or limb-threatening DVT

Insertion of a temporary inferior vena caval filter should be considered in pregnant women with acute VTE and a contraindication to anticoagulant therapy

Anticoagulant therapy for treatment of VTE during pregnancy should be continued throughout pregnancy and for at least six weeks postpartum for a minimum duration of three months 
Table 7 continued

\begin{tabular}{lc}
\hline Question & Guidance statement \\
\hline $\begin{array}{l}\text { 4. How is pregnancy- } \\
\text { associated VTE } \\
\text { prevented? }\end{array}$ & General comments \\
& All pregnant women at risk of VTE should be educated about the signs and \\
& symptoms of DVT and PE and the need to seek urgent medical attention should \\
they develop. Objective testing is mandatory if symptoms suspicious of DVT or & PE occur
\end{tabular}

All women should undergo an individualized risk assessment for VTE prior to pregnancy, once pregnancy is achieved and throughout pregnancy as new clinical situations arise

When considering the use of thrombosis prophylaxis during pregnancy and/or the postpartum period, the absolute risk of VTE, the risk reduction with prophylaxis, drawbacks of prophylaxis, and the woman's values and preferences should all be taken into account. Given the limitations of the available data, clinical vigilance rather than prophylaxis may also be acceptable for patients accepting the VTE risks quoted above and for whom the burden of LMWH prophylaxis outweighs potential benefits

If the decision is made to use antepartum prophylaxis, it should be initiated early in pregnancy

Six weeks of postpartum prophylaxis is recommended in patients with prior VTE and those with some thrombophilias. A shorter course of postpartum prophylaxis (until discharge or for one to 2 weeks post discharge) is suggested for women with transient risk factors

\section{Prevention of Recurrent VTE}

Pregnant women with prior VTE who are not receiving long-term anticoagulation should receive 6 weeks of postpartum prophylaxis

Antepartum prophylaxis should be considered in pregnant women with prior unprovoked VTE or pregnancy- or estrogen-related VTE not receiving long-term anticoagulation

Prevention of VTE in Women with Thrombophilia and no Prior VTE

Asymptomatic women who are homozygous for the factor V Leiden mutation or prothrombin gene mutation and who have a family history of VTE should receive antepartum and postpartum prophylaxis

Consideration should be given to providing postpartum prophylaxis in asymptomatic women who are heterozygous for the factor $\mathrm{V}$ Leiden mutation or prothrombin gene mutation or who have protein $\mathrm{C}$ or protein $\mathrm{S}$ deficiency and who have a family history of VTE

Given the variability in the VTE risk estimates for asymptomatic women with antithrombin deficiency and a family history of VTE, either a strategy of antepartum and postpartum prophylaxis or postpartum prophylaxis alone is reasonable

Asymptomatic women who are homozygous for the factor V Leiden mutation or prothrombin gene mutation and who have no family history of VTE should receive postpartum prophylaxis

Asymptomatic women with all other thrombophilias who do not have a family history of VTE do not require prophylaxis, in the absence of other risk factors. However, given the variability in the VTE risk estimates for asymptomatic women with antithrombin deficiency and no family history of VTE, consideration could also be given to utilizing postpartum prophylaxis in these patients

Prevention of VTE in women with clinical risk factors

Antepartum prophylaxis should be provided to immobilized (strict bedrest) women with a pre-pregnancy BMI of at least $25 \mathrm{~kg} / \mathrm{m}^{2}$ and to those with a prior history of VTE regardless of their BMI. Consideration should be given to providing prophylaxis during antepartum immobilization (as defined above) to women with a lower body mass index who have other significant comorbidities (e.g. systemic lupus erythematosus, sickle cell disease, heart disease) associated with an increased risk of VTE or a thrombophilia

Consideration should be given to providing postpartum prophylaxis while in hospital to women with a history of antepartum immobilization (as defined above) 
Table 7 continued

Question Guidance statement

for at least 7 days and to those who are immobilized postpartum who have a known thrombophilia or significant medical comorbidity

Prevention of VTE in after Cesarean Delivery

Prophylaxis should be provided after cesarean delivery to women with the following risk factors:

One or more of prior VTE, a history of antepartum immobilization (strict bedrest for at least 1 week), significant postpartum infection, postpartum hemorrhage of at least $1000 \mathrm{~mL}$ requiring re-operation, pre-eclampsia with growth restriction, significant medical co-morbidities (systemic lupus erythematosis, heart disease, or sickle cell disease) or a known thrombophilia

Two or more of (or one or more in the setting of emergency cesarean delivery) of postpartum hemorrhage of at least $1000 \mathrm{~mL}$ that does not require re-operation, BMI $>30 \mathrm{~kg} / \mathrm{m}^{2}$, fetal growth restriction, pre-eclampsia, multiple pregnancy and tobacco use during pregnancy (at least 10 cigarettes per day)

5. How is peripartum anticoagulation managed?
All pregnant women receiving anticoagulants should have an individualized delivery plan that addresses obstetrical, anesthetic and thrombotic concerns

All pregnant women should be advised to discontinue anticoagulant therapy upon the onset of spontaneous labor

If there is a planned delivery, therapeutic LMWH should be discontinued at least $24 \mathrm{~h}$ prior to the expected time of epidural analgesia or delivery. Prophylactic LMWH should be stopped at least $10-12 \mathrm{~h}$ prior to epidural analgesia

For planned deliveries, intravenously administered unfractionated heparin should be stopped at $4-6 \mathrm{~h}$ prior to the expected time of epidural analgesia or delivery and the aPTT checked to ensure normalization. For therapeutic doses of unfractionated heparin administered subcutaneously, the last dose should be given no sooner than $12 \mathrm{~h}$ and preferably closer to $24 \mathrm{~h}$ prior to expected time of epidural analgesia or delivery and the aPTT checked to ensure normalization. Guidelines differ in their requirement for a delay prior to epidural analgesia in patients receiving prophylactic dose unfractionated heparin up to 10,000 units daily; when possible prophylactic unfractionated heparin should be discontinued $8-10 \mathrm{~h}$ prior to planned procedures

Prophylactic LMWH may be started/restarted 6-12 h after delivery (no sooner than $4 \mathrm{~h}$ after epidural catheter removal), as long as hemostasis is assured and there has not been a bloody or traumatic epidural. For prophylactic unfractionated heparin, the recommended time interval from epidural catheter removal is one to $8 \mathrm{~h}$

Therapeutic LMWH may be started/restarted $24 \mathrm{~h}$ after delivery (no sooner than $24 \mathrm{~h}$ after epidural catheter removal), as long as hemostasis is assured and there has not been a bloody or traumatic epidural. Attainment of therapeutic levels of intravenous unfractionated heparin should be delayed for the same amount of time therapeutic anticoagulation [22, 23]. Discontinuation of intravenous UFH four to $6 \mathrm{~h}$ prior to the expected time of delivery or epidural insertion with a repeat activated partial thromboplastin time drawn after $4 \mathrm{~h}$ to confirm normalization will ensure that there is no residual anticoagulant effect. For the highest risk patients (e.g. VTE within 2 weeks), consideration can be given to insertion of a temporary inferior vena caval filter that can be removed postpartum.

Anticoagulants should be recommenced post-delivery as soon as adequate hemostasis is assured. Guidelines generally recommend resumption of prophylactic LMWH four to $12 \mathrm{~h}$ following delivery [17, 19]; and not sooner than $4 \mathrm{~h}$ after epidural catheter removal (with a longer delay for bloody or traumatic neuroaxial procedures) [177]. There are no definitive recommendations for resumption of fulldose LMWH following epidural catheter removal; however, it appears safe to do so $24 \mathrm{~h}$ of catheter removal (again, with a delay if placement was bloody or traumatic) $[19,22]$. The timing of resumption of postpartum vitamin $\mathrm{K}$ antagonists for patients who choose this option remains controversial; some guidelines recommend a delay of at least 5 days [21, 22], although this recommendation appears based on the results of a single centre retrospective audit [183]. Once an INR of at least 2.0 is achieved, bridging LMWH can be discontinued. 


\section{Guidance Statement}

- All pregnant women receiving anticoagulants should have an individualized delivery plan that addresses obstetrical, anesthetic and thrombotic concerns.

- All pregnant women should be advised to discontinue anticoagulant therapy upon the onset of spontaneous labor.

- If there is a planned delivery, therapeutic LMWH should be discontinued at least $24 \mathrm{~h}$ prior to the expected time of epidural analgesia or delivery. Prophylactic LMWH should be stopped at least 10-12 h prior to epidural analgesia.

- For planned deliveries, intravenously administered unfractionated heparin should be stopped at 4-6 $h$ prior to the expected time of epidural analgesia or delivery and the aPTT checked to ensure normalization. For therapeutic doses of unfractionated heparin administered subcutaneously, the last dose should be given no sooner than $12 \mathrm{~h}$ and preferably closer to $24 \mathrm{~h}$ prior to expected time of epidural analgesia or delivery and the aPTT checked to ensure normalization. Guidelines differ in their requirement for a delay prior to epidural analgesia in patients receiving prophylactic dose unfractionated heparin up to 10,000 units daily; when possible prophylactic unfractionated heparin should be discontinued 8-10 h prior to planned procedures.

- Prophylactic LMWH may be started/restarted 6-12 h after delivery (no sooner than 4 h after epidural catheter removal), as long as hemostasis is assured and there has not been a bloody or traumatic epidural. For prophylactic unfractionated heparin, the recommended time interval from epidural catheter removal is one to $8 \mathrm{~h}$.

- Therapeutic LMWH may be started/restarted $24 \mathrm{~h}$ after delivery (no sooner than $24 \mathrm{~h}$ after epidural catheter removal), as long as hemostasis is assured and there has not been a bloody or traumatic epidural. Attainment of therapeutic levels of intravenous unfractionated heparin should be delayed for the same amount of time.

\section{Conclusion}

Women are at increased risk of VTE during pregnancy and the postpartum period. Treatment and prevention of VTE in this patient population is complicated by the need to consider fetal, as well as maternal, wellbeing when making management decisions. Although our knowledge of risk factors for pregnancy-related VTE and the safe and effective use of anticoagulants used to prevent and treat VTE in this population continues to increase, there are still important gaps and high quality research in this area should be a priority. In the interim, all women should be provided with the opportunity to participate in shared decision making regarding their management. To make the best decisions, absolute risks and potential benefits of interventions, guideline recommendations, and patient values and preferences should all be taken into account. Table 7 summarizes these guidance statements.

Acknowledgments We wish to acknowledge the support provided by Myelin and Associates with the preparation of this manuscript for submission. The work contained in this manuscript was partially funded by support from the following companies: Boehringer Ingelheim, Daiichi Sankyo and Janssen Pharmaceuticals. This guidance document is endorsed by the Anticoagulation Forum's Board of Directors: Mark Crowther, MD, MSc, FRCPC, Jack E. Ansell, MD, Allison Burnett, PharmD, Nathan Clark, PharmD, Adam Cuker, MD, David Garcia, MD, Scott Kaatz, DO, MSc, FACP, Renato D. Lopes, MD, PhD, Tracy Minichiello, MD, Edith Nutescu, PharmD, FCCP, Lynn Oertel, MS, ANP, CACP, Eva Kline-Rogers, MS, RN, NP,Terri Schnurr, RN, CCRC, Michael Streiff, MD, Diane Wirth, ANP, CACP, BCPS, CACP, Daniel Witt, Pharm D, Ann Wittkowsky, PharmD, CACP, FASHP, FCCP.

\section{Compliance with ethical standards}

Disclosures SBates: salary support through the Eli Lilly Canada/ May Cohen Chair in Women's Health. S Middeldorp: reports grant support from Sanquin, grant support and fees paid to her institution from Aspen, GlaxoSmithKline, Bristol-Myers Squibb/Pfizer, and fees paid to her institution from Bayer, Boehringer Ingelheim, and Daiichi Sankyo. Recipient of a VIDI innovation research grant from the Netherlands Organization for Scientific Research. M Rodger: Recipient of a Career Investigator Award from the Heart and Stroke Foundation of Canada and a Chair in Venous Thrombosis and Thrombophilia from the Department of Medicine and Faculty of Medicine, University of Ottawa. A James: nothing to disclose. I Greer: received honoraria from Sanofi and LEO Pharma in the last 5 years.

Open Access This article is distributed under the terms of the Creative Commons Attribution 4.0 International License (http://crea tivecommons.org/licenses/by/4.0/), which permits unrestricted use, distribution, and reproduction in any medium, provided you give appropriate credit to the original author(s) and the source, provide a link to the Creative Commons license, and indicate if changes were made.

\section{References}

1. Heit JA, Kobbervig CE, James AH, Petterson TM, Bailey KR, Melton LJ 3rd (2005) Trends in the incidence of venous thromboembolism during pregnancy or postpartum: a 30-year population-based study. Ann Intern Med 143:697-706

2. Gherman RB, Goodwin TM, Leung B et al (1999) Incidence, clinical characteristics, and timing of objectively diagnosed venous thromboembolism during pregnancy. Obstet Gynecol 94:730-734

3. Lindqvist P, Dahlback B, Marsal K (1999) Thrombotic risk during pregnancy: a population study. Obstet Gynecol 94:595-599

4. Simpson EL, Lawrenson RA, Nightingale AL, Farmer RD (2001) Venous thromboembolism in pregnancy and the 
puerperium: incidence and additional risk factors from a London perinatal database. Br J Obstet Gynecol 108:56-60

5. James A, Jamison MG, Brancazio LR, Myers ER (2006) Venous thromboembolism during pregnancy and the postpartum period: incidence, risk factors, and mortality. Am J Obstet Gynecol 194:1311-1315

6. Andersen BS, Steffensen FH, Sorensen HT et al (1998) The cumulative incidence of venous thromboembolism during pregnancy and puerperium: an 11 year Danish population- based study of 63,300 pregnancies. Acta Obstet Gynecol Scand 77:170-173

7. Jacobsen AF, Skjeldestad FE, Sandset PM (2008) Incidence and risk patterns of venous thromboembolism in pregnancy and puerperium - a register-based case-control study. Am J Obstet Gynecol 198:233.e1-7

8. McColl MD, Ramsay JE, Tait RC, Walker ID, McCall F, Conkie JA, Carty MJ, Greer IA (1997) Risk factors for pregnancy associated venous thromboembolism. Thromb Haemost 78:1183-1188

9. Anderson FA Jr, Wheeler HB, Goldberg RJ et al (1991) A population-based perspective of the hospital incidence and casefatality rates of deep vein thrombosis and pulmonary embolism. The Worcester Study. Arch Intern Med 151:933-938

10. Pomp ER, Lenselink AM, Rosendaal FR, Doggen CJ (2008) Pregnancy, the postpartum period and prothrombotic defects: risk of venous thrombosis in the MEGA study. J Thromb Haemost 6:632-637

11. Kamel H, Navi BB, Sriram N, Hovsepian DA, Devereux RB, Elkind MS (2014) Risk of a thrombotic event after the 6-week postpartum period. N Engl J Med 370:1307-1315

12. McColl MD, Ellison J, Greer IA, Tait RC, Walker ID (2000) Prevalence of the post thrombotic syndrome in young women with previous venous thromboembolism. $\mathrm{Br} \mathrm{J}$ Haematol 108:272-274

13. Rosfors S, Noren A, Hjertberg R, Persson L, Lillthors K, Torngren S (2001) A 16-year haemodynamic follow-up of women with pregnancy-related medically treated iliofemoral deep venous thormbosis. Eur J Vasc Enodovasc Surg 22:448-455

14. Wik HS, Jacobsen AF, Sandvik L, Sandset PM (2012) Prevalence and predictors for post-thrombotic syndrome 3 to 16 years after pregnancy-related venous thrombosis: a population-based, crosssectional, case-control study. J Thromb Haemost 10:840-847

15. Chang J, Elam-Evans LD, Berg CJ et al (2003) Pregnancy-related mortality surveillance: United States, 1991-1999. MMWR Surveill Summ 52:1-88

16. Centre for Maternal Child Enquiries (CMACE) (2011) Saving Mothers' Lives: Reviewing Maternal Deaths to Make Motherhood Safer: 2006-2008. The eighth report on confidential enquiries into maternal deaths in the United Kingdom. BJOG 118(Suppl 1):1-203

17. James A, Committee on Practice Bulletins-Obstetrics (2011) Practice Bulletin no. 123: thromboembolism in pregnancy. Obstet Gynecol 118(3):718-729

18. Branch DW, Holmgren C, Goldberg JD, Committee on Practice Bulletins-Obstetrics (2012) Practice Bulletin no 132: antiphospholipid antibody syndrome. Obstet Gynecol 120(6):1514-1521

19. Chan WS, Rey E, Kent NE; VTE in Pregnancy Guideline Working Group, Chan WS, Kent NE, Rey E, Corbett T, David M, Douglas MJ, Gibson PS, Magee L, Rodger M, Smith RE (2014) Venous thromboembolism and antithrombotic therapy in pregnancy. J Obstet Gynaecol Can 36(6):527-53

20. Royal College of Obstetricians and Gynaecologists (2015) Green-top Guideline No. 37a. Reducing the risk of thrombosis and embolism during pregnancy and the puerperium. https:// www.rcog.org.uk/en/guidelines-research-services/guidelines/ gtg $37 \mathrm{a} /$. Accessed 10 June 2015
21. Royal College of Obstetricians and Gynaecologists (2015) Green-top Guideline No. 37b. Thromboembolic disease in pregnancy and the puerperium: acute management. https://www. rcog.org.uk/en/guidelines-research-services/guidelines/gtg37b/. Accessed 10 June 2015

22. Mclintock C, Brighton T, Chunilal S, Dekker G, McDonnell N, McRae S, Muller P, Tran H, Walters BNJ, Young L (2012) Recommendations for the diagnosis and treatment of deep venous thrombosis and pulmonary embolism in pregnancy and the postpartum period. ANZJOG 52:14-22

23. Bates SM, Greer IA, Middeldorp S, Veenstra DL, Prabulos AM, Vandvik PO, American College of Chest Physicians (2012) VTE, thrombophilia, antithrombotic therapy, and pregnancy: Antithrombotic Therapy and Prevention of Thrombosis, 9th ed: American College of Chest Physicians Evidence-Based Clinical Practice Guidelines. Chest 141(2 Suppl):e691S-e736S

24. Kearon C, Akl EA, Comerota A, Prandoni P, Bounameaux H, Goldhaber SZ, Nelson ME, Wells PS, Gould MK, Dentali F, Crowther M, Kahn SR, American College of Chest Physicians (2012) Antithrombotic therapy for VTE disease: Antithrombotic Therapy and Prevention of Thrombosis, 9th ed: American College of Chest Physicians Evidence-Based Clinical Practice Guidelines. Chest 141(2 Suppl):e419S-e3494S

25. Linkins L-A, Dans AL, Mores LK, Bona R, Davidson BL, Schulman S, Crowther M, American College of Chest Physicians (2012) Treatment and prevention of heparin-induced thrombocytopenia; Antithrombotic Therapy and Prevention of Thrombosis, 9th ed: American College of Chest Physicians Evidence-Based Clinical Practice Guidelines. Chest 141(2 Suppl):e495S-e530S

26. Rodger M (2014) Pregnancy and venous thromboembolism: 'TIPPS' for risk stratification. Hematology 2014:387-392

27. Ginsberg JS, Hirsh J, Turner CD et al (1989) Risks to the fetus of anticoagulant therapy during pregnancy. Thromb Haemost 61:197-203

28. Hall JAG, Paul RM, Wilson KM (1980) Maternal and fetal sequelae of anticoagulation during pregnancy. Am J Med 68:122-140

29. Chan WS, Anand S, Ginsberg JS (2000) Anticoagulation of pregnant women with mechanical heart valves: a systematic review of the literature. Arch Intern Med 160:191-196

30. Hassouna A, Allam H (2010) Anticoagulation of pregnant women with mechanical heart valve prosthesis: a systematic review of the literature (2000-2009). J Coagul Disorders 2:81-88

31. Pauli RM, Haun J (1993) Intrauterine effects of coumarin derivatives. Dev Brain Dysfunct 6:229-247

32. Schaefer C, Hannemann D, Meister R et al (2006) Vitamin K antagonists and pregnancy outcome. A multi-centre prospective study. Thromb Haemost 95:949-957

33. Hirsh J, Cade JF, O'Sullivan EF (1970) Clinical experience with anticoagulant therapy during pregnancy. Br Med J 1:270-273

34. van Driel D, Wesseling J, Sauer PJJ et al (2001) In utero exposure to coumarins and cognition at 8 to 14 years old. Pediatr 107:123-129

35. Boehringer Ingelheim. Prescribing information: Pradaxa. Date of text revision: 09/2014. http://bidocs.boehringer-ingelheim. com/BIWebAccess/ViewServlet.ser?docBase=renetnt $\&$ folder Path=Prescribing\%20Information/PIs/Pradaxa/Pradaxa.pdf

36. Janssen Pharmaceuticals. Prescribing information: Xarelto. Date of text revision: 09/2014. http://www.xareltohcp.com/sites/ default/files/pdf/xarelto_0.pdf

37. Bristol-Myers Squibb. Prescribing information: Eliquis. Date of text revision: 08/2014. http://packageinserts.bms.com/pi/pi_eli quis.pdf 
38. Tang A-W, Greer I (2013) A systematic review on the use of the new anticoagulants in pregnancy. Obstet Med 6:64-71

39. Dempfle CE (2004) Minor transplacental passage of fondaparinux in vivo. N Engl J Med 350:1914-1915 (Letter)

40. Harenberg J (2007) Treatment of a woman with lupus and thromboembolism and cutaneous intolerance of heparins using fondaparinux during pregnancy. Thromb Res 119:385-388

41. Mazzolai L, Hohfeld P, Spertini F et al (2006) Fondaparinux is a safe alternative in case of heparin intolerance during pregnancy. Blood 108:1569-1570

42. Wijesiriwardana A, Lees DA, Lush C (2006) Fondaparinux as anticoagulant in a pregnant woman with heparin allergy. Blood Coagul Fibrinolysis 17:147-149

43. Gerhardt A, Zotz RB, Stockschlaeder M, Eberhard R, Scharf E (2007) Fondaparinx is an effective alternative anticoagulant in pregnant women with high risk for thromboembolism and intolerance to low molecular weight heparin and heparinoids. Thromb Haemost 97:496-497

44. Winger EE, Reed JL (2009) A retrospective analysis of fondaparinux versus enoxaparin treatment in women with infertility or pregnancy loss. Am J Reprod Immunol 2:253-260

45. Knol HM, Schultinge L, Erwich JJHM, Meijer K (2010) Fondaparinux as an alternative anticoagulant therapy during pregnancy. J Thromb Haemost 8:1876-1879

46. Elsaigh E, Thachil J, Nash MJ, Tower C, Hay CR, Bullough S, Byrd L (2014) The use of fondaparinux in pregnancy. Br J Haematol. doi:10.1111/bjh.13147. [Epub ahead of print]

47. Flessa HC, Kapstrom AB, Glueck HI et al (1965) Placental transport of heparin. Am J Obstet Gynecol 93:570-573

48. Clark NP, Delate T, Witt DM, Parker S, McDuffie R (2009) A descriptive evaluation of unfractionated heparin use during pregnancy. J Thromb Thrombolysis 27:267-273

49. Ginsberg JS, Kowalchuk G, Hirsh J et al (1989) Heparin therapy during pregnancy: risks to the fetus and mother. Arch Intern Med 149:2233-2236

50. Forestier F, Daffos F, Capella-Pavlovsky M (1984) Low molecular weight heparin (PK 10169) does not cross the placenta during the second trimester of pregnancy: study by direct fetal blood sampling under ultrasound. Thromb Res 34:557-560

51. Forestier F, Daffos F, Rainaut M, Toulemonde F (1987) Low molecular weight heparin (CY 216) does not cross the placenta during the third trimester of pregnancy. Thromb Haemost 57:234

52. Peeters LLH, Hobbelen PMJ, Verkeste CM et al (1986) Placental transfer of Org 10172, a low-molecular-weight heparinoid in the awake late-pregnant guinea pig. Thromb Res 44:277-283

53. Henny CP, ten Cate H, ten Cate JW et al (1986) Thrombosis prophylaxis in an AT III deficient pregnant woman: application of a low molecular-weight heparinoid. Thromb Haemost 55:301 (letter)

54. Greinacher A, Eckhrdt T, Mussmann J, Mueller-Eckhardt C (1993) Pregnancy-complicated by heparin associated thrombocytopenia: management by a prospectively in vitro selected heparinoid (Org 10172). Thromb Res 71:123-126

55. Lindhoff-Last E, Kreutzenbeck H-J, Magnani HN (2005) Treatment of 51 pregnancies with danaparoid because of heparin intolerance. Thromb Haemost 93:63-69

56. Warkentin TE, Levine MN, Hirsh J et al (1994) Heparin induced thrombocytopenia in patients treated with low molecular weight heparin or unfractionated heparin. N Engl J Med 332:1330-1335

57. Weitz JI (1997) Low-molecular-weight heparin. N Engl J Med 337:688-698

58. Sanson BJ, Lensing AWA, Prins MH et al (1999) Safety of lowmolecular-weight heparin in pregnancy: a systematic review. Thromb Haemost 81:668-672

59. Greer IA, Nelson Piercy C (2005) Low molecular weight heparins for thromboprophylaxis and treatment of venous thromboembolism in pregnancy: a systematic review of safety and efficacy. Blood 106:401-407

60. Romualdi E, Dentali F, Rancan E, Squizzato A, Steidl L, Middeldorp S, Ageno W (2013) Anticoagulant therapy for venous thromboembolism during pregnancy: a systematic review and a meta-analysis of the literature. J Thromb Haemost 11:270-281

61. Lepercq J, Conard J, Borel-Derlon A et al (2001) Venous thromboembolism during pregnancy: a retrospective study of enoxaparin safety in 624 pregnancies. $\mathrm{Br} \mathrm{J}$ Obstet Gynaecol 08:1134-1140

62. Pettila V, Leinonen P, Markkola A et al (2002) Postpartum bone mineral density in women treated with thromboprophylaxis with unfractionated heparin or LMW heparin. Thromb Haemost 87:182-186

63. Carlin AJ, Farquharson RG, Quenby SM et al (2004) Prospective observational study of bone mineral density during pregnancy: low molecular-weight heparin versus control. Hum Reprod 19:1211-1214

64. Rodger MA, Kahn SR, Cranney A, Hodsman A, Kovacs MJ, for the TIPPS Investigators et al (2007) Long-term dalteparin in pregnancy not associated with a decrease in bone mineral density: substudy of a randomized controlled trial. J Thromb Haemost 5:1600-1606

65. Lefkou E, Khamashta M, Hampson G, Hunt BJ (2010) Lowmolecular-weight heparin-induced osteoporosis and osteoporotic fractures: a myth or an existing entity? Lupus 19:3-12

66. Byrd LM, Schiach CR, Hay CRM, Johnston TA (2008) Osteopenic fractures in pregnancy: Is low molecular weight heparin (LMWH) implicated? J Obst and Gynaecol 28:539-542

67. Le Templier G, Rodger MA (2008) Heparin-induced osteoporosis and pregnancy. Curr Opin Pulm Med 14:403-407

68. Bank I, Libourel EJ, Middeldorp S, van der Meer J, Buller HR (2003) High rate of skin complications due to low molecular weight heparin in pregnant women. J Thromb Haemost 1:859-861

69. Wutschert R, Piletta P, Bounameuaux H (1999) Adverse skin reactions to low molecular weight heparins: frequency, management and prevention. Drug Saf 20:515-525

70. Lim W, Dentali F, Eikelboom JW, Crowther MA (2006) Metaanalysis: low-molecular-weight heparin and bleeding in patients with severe renal insufficiency. Ann Intern Med 144(9):673-684

71. Orme ML, Lewis PJ, de Swiet M et al (1977) May mothers given warfarin breast-feed their infants? Br Med J 1:1564-1565

72. McKenna R, Cole ER, Vasan V (1983) Is warfarin sodium contraindicated in the lactating mother? J Pediatr 103:325-327

73. Houwert-de Jong M, Gerards LJ, Tetteroo-Tempelman CAM, de Wolff FA (1981) May mothers taking acenocoumarol breast feed their infants? Eur J Clin Pharmacol 21:61-64

74. Fondavilla CG, Meschengieser S, Blanco A, Penalva L, Lazzari MA (1989) Effect of acenocoumarine on the breast-fed infant. Thromb Res 56:29-36

75. Olthof E, de Vries TW (1993) Breast feeding and oral anticoagulants. Tijdschr Kindergeneeskd 61:175-177

76. von Kries R, Nocker D, Schmitz-Kummer E, de Vries JX (1993) Transfer of phenprocoumon in breast milk. Is oral anticoagulation with phenprocoumon a contraindication for breastfeeding? Monatsschr Kinderheilkd 141:505-507

77. Richter C, Sitzmann J, Lang P et al (2001) Excretion of lowmolecular-weight heparin in human milk. Br J Clin Pharmacol 52:708-710

78. GlaxoSmithKline. Prescribing Information: Arixtra. Date of test revision: 09/2013. https://www.gsksource.com/gskprm/htdocs/ documents/ARIXTRA-PI-PIL.PDF

79. Vetter A, Perera G, Leithner K, Klima G, Bernkop-Schnurch A (2010) Development and in vivo bioavailability study of an oral fondaparinux delivery system. Eur J Pharm Sci 41:489-497 
80. Konstantinides SV, Torbicki A, Agnelli G, Danchin N, Fitzmaurice D, Galiè N, Gibbs JS, Huisman MV, Humbert M, Kucher N, Lang I, Lankeit M, Lekakis J, Maack C, Mayer E, Meneveau N, Perrier A, Pruszczyk P, Rasmussen LH, Schindler TH, Svitil P, Vonk Noordegraaf A, Zamorano JL, Zompatori M, Authors/Task Force Members (2014) ESC Guidelines on the diagnosis and management of acute pulmonary embolism: The Task Force for the Diagnosis and Management of Acute Pulmonary Embolism of the European Society of Cardiology (ESC)—Endorsed by the European Respiratory Society (ERS). Eur Heart J 35:3033-3073. doi:10.1093/eurheartj/ehu283 Epub 2014 Aug 29

81. Gould MK, Dembitzer AD, Doyle RL et al (1999) Lowmolecular-weight heparins compared with unfractionated heparin for treatment of acute venous thrombosis: a meta-analysis of randomized, controlled trials. Ann Intern Med 130:800-809

82. Quinlan DJ, McMillan A, Eikelboom JW (2004) Low-molecular-weight heparin compared with intravenous unfractionated heparin for treatment of pulmonary embolism: a meta-analysis of randomized controlled trials. Ann Intern Med 140:175-183

83. van der Heijden JF, Hutten BA, Buller HR, et al (2000) Vitamin $\mathrm{K}$ antagonists or low-molecular-weight heparin for the longterm treatment of symptomatic venous thromboembolism. Cochrane Database Syst Rev 2000; CD002001

84. Lee AYY, Levine MN, Baker RI et al (2003) Low-molecularweight heparin versus a coumarin for the prevention of recurrent venous thromboembolism in patients with cancer. N Engl J Med 349:146-153

85. Voke J, Keidan J, Pavord S, Spencer HN, Hunt BJ, on behalf of the British Society of Haematology Obstetric Haematology Group (2007) The management of antenatal venous thromboembolism in the UK and Ireland: a prospective multicentre observational study. Br J Haematol 139:545-558

86. Knight M, on behalf of UKOSS (2008) Antenatal pulmonary embolism: risk factors, management and outcomes. BJOG 115:453-461

87. Barbour LA, Oja JL, Schultz LK (2004) A prospective trial that demonstrates that dalteparin requirements increase in pregnancy to maintain therapeutic levels of anticoagulation. Am J Obstet Gynecol 191:1024-1029

88. Jacobsen AF, Qvisgstad E, Sandset PM (2002) Low molecular weight heparin (dalteparin) for treatment of venous thromboembolism in pregnancy. Br J Obstet Gynaecol 110:139-144

89. Crowther MA, Spitzer K, Julian J et al (2000) Pharmacokinetic profile of a low-molecular weight heparin (Reviparin) in pregnant patients: a prospective cohort study. Thromb Res 98:133-138

90. Rodie VA, Thomson AJ, Stewart FM et al (2002) Low molecular weight heparin for the treatment of venous thromboembolism in pregnancy: case series. $\mathrm{Br} \mathrm{J}$ Obstet Gynaecol 109:1020-1024

91. Rey E, Rivard GE (2000) Prophylaxis and treatment of thromboembolic diseases during pregnancy with dalteparin. Int $\mathrm{J}$ Gynecol Obstet 71:19-24

92. Smith MP, Norris LA, Steer PJ, Savidge GF, Bonnar J (2004) Tinzaparin sodium for thrombosis treatment and prevention during pregnancy. Am J Obstet Gynecol 190:495-501

93. Patel JP, Green B, Patel RK, Marsh MS, Davies JG, Arya R (2013) Population pharmacokinetics of enoxaparin during the antenatal period. Circulation 128:1462-1569

94. Nelson-Piercy C, Powrie R, Borg JY, Rodger M, Talbot DJ, Stinson J et al (2011) Tinzaparin use in pregnancy: an international retrospective safety of the safety and efficacy profile. Eur J Obstet Gynecol Reprod Biol 159:293-299

95. Bhutia S, Wong PF (2013) Once versus twice daily low molecular weight heparin for the initial treatment of venous thromboembolism. Cochrane Database Syst Rev 7:CD003074. doi:10.1002/14651858.CD003074.pub3

96. Kovacs MJ, Keeney M, MacKinnon K, Boyle E (1999) Three different chromogenic methods do not give equivalent anti-Xa levels for patients on therapeutic low molecular weight heparin (dalteparin) or unfractionated heparin. Clin Lab Haematol 21:55-60

97. Kitchen S, Iampietro R, Woolley AM, Preston FE (1999) Anti Xa monitoring during treatment with low molecular weight heparin or danaparoid: inter-assay variability. Thromb Haemost 82:1289-1293

98. Monreal M, Lafoz E, Olive A et al (1994) Comparison of subcutaneous unfractionated heparin with low molecular weight heparin (Fragmin) in patients with venous thromboembolism and contraindications to coumarin. Thromb Haemost 71:7-11

99. Gandara E, Carrier M, Rodger MA (2014) Intermediate doses of low-molecular weight-heparin for the long-term treatment of pregnancy thromboembolism. A systematic review. Thromb Haemost 111:559-561

100. Gandara E, Carrier M, Rodger MA (2014) Management of pregnancy-associated venous thromboembolism. Thrombosis $\mathbf{J}$ 12:12

101. Hull RD, Delmore TJ, Carter CJ et al (1982) Adjusted subcutaneous heparin versus warfarin sodium in the long-term treatment of venous thromboembolism. N Engl J Med 306:189-194

102. Chunilal SD, Young E, Johnston MA et al (2000) The aPTT response of pregnant plasma to unfractionated heparin. Thromb Haemost 87:92-97

103. Pfeifer GW (1970) Distribution studies and placental transfer of 131 I streptokinase. Australas Ann Med 19(Suppl 1):17-18

104. Leonhardt G, Gaul C, Nietsch HH, Buerke M, Schleussner E (2006) Thrombolytic therapy in pregnancy. J Thromb Thrombolysis $21: 271-276$

105. Ahearn GS, Hadjilaiadis D, Govert JA, Tapson VF (2002) Massive pulmonary embolism during pregnancy treated with recombinant tissue plasminogen activator. A case report and review of treatment options. Arch Intern Med 162:1221-1226

106. Doreen te Raa G, Ribbert LSM, Snijder RJ, Biesma DH (2009) Treatment options in massive pulmonary embolism during pregnancy: a case report and review of the literature. Thromb Res 124:1-5

107. Holden EL, Ranu H, Sheth Abhijat (2011) Thrombolysis for massive pulmonary embolism in pregnancy-a report of three cases and follow-up over a two year period (Letter to the Editors-in-Chief). Thromb Res 127:58-59

108. Gupta S, Ettles DF, Robinson GJ, Lindow SW (2008) Inferior vena cava filter use in pregnancy: preliminary experience. BJOG 115(6):785-788

109. Cheung MC, Asch MR, Gandhi S, Kingdom JCP (2005) Temporary inferior vena caval filter use in pregnancy. $\mathrm{J}$ Thromb Haemost 3:1076-1079

110. Ganguli S, Tham JC, Komlos F, Rabkin DJ (2006) Fracture and migration of a suprarenal inferior vena cava filter in a pregnant patient. J Vasc Interv Radiol 17:1707-1711

111. Milford W, Chadha Y, Lust K (2009) Use of a retrievable inferior vena cava filter in term pregnancy: case report and review of the literature. Aust NZ J Obstet Gynaecol 49:331-333

112. McConville RM, Kennedy PT, Collins AJ, Ellis PK (1998) Failed retrieval of an inferior vena cava filter during pregnancy because of filter tilt: report of two cases. Cardiovasc Intervent Radiol 32:174-177

113. Carrier M, Le Gal G, Cho R, Tierney S, Rodger M, Lee AY (2009) Dose-escalation of low molecular weight heparin to manage recurrent venous thromboembolic events despite systemic anticoagulation in cancer patients. J Thromb Haemost 7:760-765 
114. Iladdadene R, Le Gal G, Delluc A, Carrier M (2014) Dose escalation of low molecular weight heparin in patients with recurrent cancer-associated thrombosis. Thromb Res 134:93-95

115. Brandjes DPM, Buller HR, Heijboer H, Huisman MV, de Rijk M, Jagt H, ten Cate JW (1997) Randomised trial of effect of compression stockings in patients with symptomatic proximalvein thrombosis. Lancet 349:759-762

116. Prandoni $\mathrm{P}$, Lensing AWA, Prins MH, Fulla M, Marchiori A, Bernardi E, Tormene D, Mosena L, Pagnan A, Girolami A (2004) Below-knee elastic compression stockings to prevent the post-thrombotic syndrome: a randomized, controlled trial. Ann Intern Med 141:249-256

117. Kahn SR, Shapiro S, Wells PS, Rodger MA, Kovacs MJ, Anderson DR, Tagalakis V, Houweling AH, Ducruet T, Holcroft C, Johri M, Solymoss S, Miron MJ, Yeo E, Smith R, Schulman S, Kassis J, Kearon C, Chagnon I, Wong T, Demers C, Hanmiah R, Kaatz S, Selby R, Rathbun S, Desmarais S, Opatrny L, Ortel TL, Ginsberg JS; SOX trial investigators (2014) Compression stockings to prevent post-thrombotic syndrome: a randomised placebo-controlled trial. Lancet 383(9920):880-888. doi:10. 1016/S0140-6736(13)61902-9. Epub 2013 Dec 6

118. Kahn SR, Shapiro S, Ducruet T, Wells PS et al (2014) Graduated compression stockings to treat acute leg pain associated with proximal DVT: a randomised controlled trial. Thromb Haemost 112(6): 1137-1141

119. Bain E, Wilson A, Tooher R, Gates S, Davies L-J, Middleton P (2014) Prophylaxis for venous thromboembolic disease in pregnancy and the early postnatal period. Cochrane Database of Systematic Reviews Issue 2. Art. No.: CD001689

120. Ray JG, Chan WS (1999) Deep vein thrombosis during pregnancy the puerperium: a meta-analysis of the period of risk and the leg of presentation. Obstet Gynecol Surv 54:265-271

121. Blanco-Molina A, Trujillo-Santos J, Criado J, Lopez L, Lecumberri R, Gutierrez R, Monreal M, Investigators RIETE (2007) Venous thromboembolism during pregnancy or postpartum: findings from the RIETE Registry. Thromb Haemost 97:186-190

122. Broekmans AW, Bertina RM, Loeliger EA, Hofmann V, Klingemann HG (1983) Protein C and the development of skin necrosis during anticoagulant therapy. Thromb Haemost 49:251

123. Locht H, Lindstrom FD (1993) Severe skin necrosis following warfarin therapy in a patient with protein $\mathrm{C}$ deficiency. J Intern Med 233:287-289

124. Berkompas DC (1991) Coumadin skin necrosis in a patient with a free protein $\mathrm{S}$ deficiency: case report and literature review. Indiana Med 84:788-791

125. Gates S, Brocklehurst P, Ayers S, Bowler U (2004) Thromboprophylaxis and pregnancy: two randomized controlled pilot trials that used low-molecular-weight heparin. Am J Obstet Gynecol 191:1296-1303

126. Pettila V, Kaaja R, Leinonen P, Ekblad U, Kataja M, Ikkala E (1999) Thromboprophylaxis with low molecular weight heparin (dalteparin) in pregnancy. Thromb Res 96:275-282

127. Rozanski C, Lazo-Langner A, Kovacs M (2009) Prevention of venous thromboembolism (VTE) associated with pregnancy in women with a past history of VTE. Blood Supplement abstract \# $3132 \mathrm{ASH}$

128. Blomback M, Bremme K, Hellgren M, Siegbahn A, Lindberg H (1998) Thromboprophylaxis with low molecular mass heparin, 'Fragmin' (dalteparin), during pregnancy—a longitudinal safety study. Blood Coagul Fibrinolysis 9:1-9

129. Brennand JE, Walker ID, Greer IA (1999) Anti-activated factor $\mathrm{X}$ profiles in pregnant women receiving antenatal thromboprophylaxis with enoxaparin. Acta Haematol 101:53-55
130. Dargaud Y, Rugeri L, Vergnes MC, Arnuti B, Miranda P, Negrier C, Bestion A, Desmurs-Clavel H, Ninet J, Gaucherand P, Rudigoz RC, Berland M, Champion F, Trzeciak MC (2009) A risk score for the management of pregnant women with increased risk of venous thromboembolism: a multicentre prospective study. Br J Haematol 145:825-835

131. Folkeringa N, Brouwer JL, Korteweg FJ, Veeger NJ, Erwich JJ, van der Meer J (2007) High risk of pregnancy-related venous thromboembolism in women with multiple thrombophilic defects. Br J Haematol 138:110-116

132. Dulitzky M, Pauzner H, Langevitz P, Pras M, Many A, Schiff E (1996) Low-molecular-weight heparin during pregnancy and delivery: preliminary experience with 41 pregnancies. Obstet Gynecol 87:380-383

133. Casele HL, Laifer SA, Woelkers DA, Venkataramanan R (1999) Changes in the pharmacokinetics of the low-molecular-weight heparin enoxaparin sodium during pregnancy. Am J Obstet Gynecol 181(5 Pt 1):1113-1137

134. Roeters van Lennep JE, Meijer E, Klumper FJ, Middeldorp JM, Bloemenkamp KW, Middeldorp S (2011) Prophylaxis with low dose low molecular weight heparin during pregnancy and postpartum: is it effective? J Thromb Haemost 9:473-480

135. Galambosi Paivi J, Ulander V-M, Kaaja RJ (2014) The incidence and risk factors of recurrent venous thromboembolism. Thromb Res 134:240-245

136. Gould MK, Garcia DA, Wren SM, Karanicolas PJ, Arcelus JI, Heit JA, Samama CM, American College of Chest Physicians (2012) Prevention of VTE in nonorthopedic surgical patients: antithrombotic therapy and prevention of thrombosis, 9th ed: American College of Chest Physicians evidence-based clinical practice guidelines. Chest 141(2):e227s-e277s

137. Sultan AA, Grainge MJ, West J, Fleming KM, Nelson-Piercy C, Tata LJ (2014) Impact of risk factors on the timing of first postpartum venous thromboembolism: a population-based cohort study from England. Blood 124:28872-28880

138. Pabinger I, Grafenhofer H, Kyrle PA, Quehenberger P, Mannhalter C, Lechner K et al (2002) Temporary increase in the risk for recurrence during pregnancy in women with a history of venous thromboembolism. Blood 100:1060-1062

139. Brill-Edwards P, Ginsberg JS, Gent M, Hirsh J, Burrows R, Kearon C et al (2000) Safety of withholding heparin in pregnant women with a history of venous thromboembolism. N Eng J Med 343:1439-1444

140. Pabinger I, Grafenhofer H, Kaider A, Kyrle PA, Quehenberger P, Mannhalter C et al (2005) Risk of pregnancy-associated recurrent venous thromboembolism in women with a history of venous thrombosis. J Thromb Haemost 3:949-954

141. De Stefano V, Martinelli I, Rossi E, Battaglioli T, Za T, Mannuccio MP et al (2006) The risk of recurrent venous thromboembolism in pregnancy and puerperium without antithrombotic prophylaxis. Br J Haematol 135:386-391

142. Middeldorp S (2011) Is thrombophilia testing useful? Hematology (Am Hem Soc Hematol Educ Program) 2011:150-155

143. White RH, Chan WS, Zhou H, Ginsberg JS (2008) Recurrent venous thromboembolism after pregnancy-associated versus unprovoked thromboembolism. Thromb Haemost 100:246-252

144. Greer IA (1999) Thrombosis in pregnancy: maternal and fetal issues. Lancet 10(353):1258-1265

145. Middeldorp S, van Hylckama Vlieg A (2008) Does thrombophilia testing help in the clinical management of patients? Br J Haematol 143:321-335

146. Robertson L, Wu O, Langhorne P et al (2005) for The Thrombosis Risk and Economic Assessment of Thrombophilia Screening (Treats) Study: thrombophilia in pregnancy: a systematic review. Br J Haematol 132:71-196 
147. Bezemer ID, van der Meer FJ, Eikenboom JC, Rosendaal FR, Doggen CJ (2008) The value of family history as a risk indicator for venous thrombosis. Arch Intern Med 169:610-615

148. Zoller B, Ohlsson H, Sundquist J, Sundquist K (2013) Familial risk of venous thromboembolism in first-, second- and thirddegree relatives: a nation-wide family study in Sweden. Thromb Haemost 109:361-362

149. Lensen RP, Bertina RM, de Ronde H, Vandenbroucke JP, Rosendaal FR (2000) Venous thrombotic risk in family members of unselected individuals with factor $\mathrm{V}$ Leiden. Thromb Haemost 83:817-821

150. Friederich PW, Sanson BJ, Simioni P, Zanardi S, Huisman MV, Kindt I et al (1996) Frequency of pregnancy-related venous thromboembolism in anticoagulant factor-deficient women: implications for prophylaxis. Ann Int Med 125:955-960

151. Mahmoodi BK, Brouwer J-LP, Ten Kate MK, Lijfering WM, Veeger NJGM, Mulder AB, Kluin-Nelemans HC, van der Meer J (2010) A prospective cohort study on the absolute risks of venous thromboembolism and predictive value of screening asymptomatic relatives of patients with hereditary deficiencies of protein $\mathrm{S}$, protein $\mathrm{C}$ and antithrombin. $\mathrm{J}$ Thromb Haemost $8: 1193-1200$

152. Middeldorp S, Libourel EJ, Hamulyak K, van der Meer J, Buller HR (2001) The risk of pregnancy-related venous thromboembolism in women who are homozygous for factor V Leiden. Br J Haematol 113:553-555

153. Martinelli I, Legnani C, Bucciarelli P, Grandone E, De Stefano V, Mannucci PM (2001) Risk of pregnancy-related venous thrombosis in carriers of severe inherited thrombophilia. Thromb Haemost 86:800-803

154. Tormene D, Simioni P, Prandoni P, Luni S, Zerbinati P, Sartor D et al (2001) Factor V Leiden mutation and the risk of venous thromboembolism in pregnant women. Haematologica 86:1305-1309

155. Middeldorp S, Henkens CMA, Koopman MMW, van Pampus ECM, van der Meer J, Hamulyak K et al (1998) The incidence of venous thromboembolism in family members of patients with factor V Leiden mutation and venous thrombosis. Ann Int Med 128:15-20

156. Simioni P, Sanson BJ, Prandoni P, Tormene D, Friederich PW, Girolami B et al (1999) The incidence of venous thromboembolism in families with inherited thrombophilia. Thromb Haemost 81:198-202

157. Middeldorp S, Meinardi JR, Koopman MMW, van Pampus ECM, Hamulyak K, van der Meer J et al (2001) A prospective study of asymptomatic carriers of the factor $\mathrm{V}$ Leiden mutation to determine the incidence of venous thromboembolism. Ann Int Med 135:322-327

158. Simioni P, Tormene DF, Prandoni PF, Zerbinati PF, Gavasso S, Cefalo $P$ et al (2002) Incidence of venous thromboembolism in asymptomatic family members who are carriers of factor $\mathrm{V}$ Leiden: a prospective cohort study. Blood 99:1938-1942

159. Couturaud F, Leroyer C, Mottier D (2008) Risk factors and clinical presentation of venous thromboembolism according to the age of relatives of patients with factor $\mathrm{V}$ Leiden. Thromb Haemost 99:793-794

160. Bank I, Libourel EJ, Middeldorp S, van Pampus ECM, Koopman MMW, Hamulyak K et al (2004) Prothrombin 20210A mutation: a mild risk factor for venous thromboembolism but not for arterial thrombotic disease and pregnancy-related complications in a family study. Arch Int Med 164:1932-1937

161. Coppens M, van der Poel MH, Bank I, Hamulyak K, van der Meer J, Veeger NJ et al (2006) A prospective cohort study on the absolute incidence of venous thromboembolism and arterial cardiovascular disease in asymptomatic carriers of the prothrombin 20210A mutation. Blood 108:2604-2607
162. Galli M, Barbui T (2005) Antiphospholipid syndrome: clinical and diagnostic utility of laboratory tests. Semin Thromb Hemost 31:17-24

163. Bergrem A, Jacobsen EM, Skjeldestad FE, Jacobsen AF, Skogstad M, Sandset PM (2010) The association of antiphospholipid antibodies with pregnancy-related first time venous thrombosis-a population-based case-control study. Thromb Res 125:e222-e227

164. Quenby S, Farquharson RG, Dawood F, Hughes AM, Topping J (2005) Recurrent miscarriage and long-term thrombosis risk: a case-control study. Hum Reprod 20:1729-1732

165. Conard J, Horellou MH, van Dreden P, Lecompte T, Samama M (1990) Thrombosis and pregnancy in congenital deficiencies in AT III, protein C or protein S: study of 78 women. Thromb Haemost 63:319-320

166. De Stefano V, Leone G, Mastrangelo S, Tripodi A, Rodeghiero F, Castaman G, Barbui T, Finazzi G, Bizzi B, Mannucci PM (1994) Thrombosis during pregnancy and surgery in patients with congenital deficiency of antithrombin III, protein C, and protein S. Thromb Haemost 71:799-800

167. Vincente V, Rodriguez C, Soto I, Fernandez M, Moraleda JM (1994) Risk of thrombosis during pregnancy and post-partum in hereditary thrombophilia. Am J Hematol 46:151-152

168. Henriksson P, Westerlund E, Wallén H, Brandt L, Hovatta O, Ekbom A (2013) Incidence of pulmonary and venous thromboembolism in pregnancies after in vitro fertilisation: cross sectional study. BMJ:346:e8632. doi:10.1136/bmj.e8632

169. Jacobsen AF, Skjeldestad FE, Sandset PM (2008) Ante- and postnatal risk factors of venous thrombosis: a hospital-based case-control study. J Thromb Haemost 6:905-912

170. Kevane B, Donnelly J, D’Alton M, Cooley S, Roger JSP, Ni Ainle F (2014) Risk factors for pregnancy-associated venous thromboembolism: a review. J Perinat Med 42:417-425

171. Sultan AA, Tata LJ, West J, Fiaschi L, Fleming KM, NelsonPiercy C, Grainge M (2013) Risk factors for first venous thromboembolism around pregnancy: a population-based cohort study from the United Kingdom. Blood 121:3953-3961

172. Kane EV, Calderwood C, Dobbie R, Morris C, Roman E, Greer IA (2013) A population-based study of venous thrombosis in Scotland 1980-2005. Eur J Obstet Gynecol Reprod Biol 169:223-229

173. Jacobsen AF, Drolsum A, Ne Klow, Dahl GF, Qvigstad E, Sandset PM (2004) Deep vein thrombosis after elective cesarean section. Thromb Res 113:283-288

174. Sia WW, Powrie RO, Cooper AB, Larson L, Phipps M, Spencer P, Sauve N, Rosene-Montella K (2009) The incidence of deep vein thrombosis in women undergoing cesarean delivery. Thromb Res 123:550-550

175. Macklon SN, Greer IA (1994) Venous thromboembolic disease in obstetrics and gynaecology: the Scottish experience. Scott Med J 41:83-86

176. Ruppen W, Derry S, McQuay H, Moore RA (2006) Incidence of epidural hematoma, infection, and neurologic injury in obstetric patients with epidural analgesia/anesthesia. Anesthesiology 105(2):394-399

177. Narouze S, Benzon H, Provenzano DA et al (2015) Interventional Spine and Pain Procedures in Patients on Antiplatelet and Anticoagulant Medications: Guidelines From the American Society of Regional Anesthesia and Pain Medicine, the European Society of Regional Anaesthesia and Pain Therapy, the American Academy of Pain Medicine, the International Neuromodulation Society, the North American Neuromodulation Society, and the World Institute of Pain. Reg Anesth Pain Med 40:182-212

178. Anderson DR, Ginsberg JS, Burrow R, Brill-Edwards P (1991) Subcutaneous heparin therapy during pregnancy: a need for concern at the time of delivery. Thromb Haemost 65:248-250 
179. Greer IA (2012) Thrombosis in pregnancy: updates in diagnosis and management. Hematol Am Soc Hematol Educ Program 2012:203-207

180. Massonnet-Castel S, Pelissier E, Bara L et al (1986) Partial reversal of low molecular-weight heparin (PK 101699) anti-Xa activity by protamine sulfate: in vitro and in vivo study during cardiac surgery with extracorporeal circulation. Haemostasis $16: 139-146$

181. Investigators Columbus (1997) Low-molecular-weight heparin in the treatment of patients with venous thromboembolism. N Engl J Med 337:657-662
182. Kearon C, Hirsh J (1997) Management of anticoagulation before and after elective surgery. N Engl J Med 336:1506-1511

183. McLintock C, McCowan LM, North RA (2009) Maternal complications and pregnancy outcome in women with mechanical prosthetic heart valves treated with enoxaparin. BJOG 116:1585-1592 